\title{
Membrane-associated collagens with interrupted triple-helices (MACITs): evolution from a bilaterian common ancestor and functional conservation in $C$. elegans
}

Hongmin Tu${ }^{1}$, Pirkko Huhtala ${ }^{1}$, Hang-Mao Lee ${ }^{1}$, Josephine C. Adams ${ }^{2^{*}}$ and Taina Pihlajaniemi ${ }^{{ }^{*}}$

\begin{abstract}
Background: Collagens provide structural support and guidance cues within the extracellular matrix of metazoans. Mammalian collagens XIII, XXIII and XXV form a unique subgroup of type II transmembrane proteins, each comprising a short N-terminal cytosolic domain, a transmembrane domain and a largely collagenous ectodomain. We name these collagens as MACITs (Membrane-Associated Collagens with Interrupted Triple-helices), and here investigate their evolution and conserved properties. To date, these collagens have been studied only in mammals. Knowledge of the representation of MACITs in other extant metazoans is lacking. This question is of interest for understanding structural/ functional relationships in the MACIT family and also for insight into the evolution of MACITs in relation to the secreted, fibrillar collagens that are present throughout the metazoa.

Results: MACITs are restricted to bilaterians and are represented in the Ecdysozoa, Hemichordata, Urochordata and Vertebrata (Gnathostomata). They were not identified in available early-diverging metazoans, Lophotrochozoa, Echinodermata, Cephalochordata or Vertebrata (Cyclostomata). Whereas invertebrates encode a single MACIT, collagens XIII/XXIII/XXV of jawed vertebrates are paralogues that originated from the two rounds of en-bloc genome duplication occurring early in vertebrate evolution. MACITs have conserved domain architecture in which a juxta-membrane furin-cleavage site and the C-terminal 34 residues are especially highly conserved, whereas the cytoplasmic domains are weakly conserved. To study protein expression and function in a metazoan with a single MACIT gene, we focused on Caenorhabditis elegans and its col-99 gene. A col-99 cDNA was cloned and expressed as protein in mammalian $\mathrm{CHO}$ cells, two antibodies against COL-99 protein were generated, and a col-99-bearing fosmid gene construct col-99::egfp::flag was used to generate transgenic C. elegans lines. The encoded COL-99 polypeptide is $85 \mathrm{kDa}$ in size and forms a trimeric protein. COL-99 is plasma membrane-associated and undergoes furin-dependent ectodomain cleavage and shedding. COL-99 is detected in mouth, pharynx, body wall and the tail, mostly in motor neurons and muscle systems and is enriched at neuromuscular junctions.

(Continued on next page)
\end{abstract}

\footnotetext{
* Correspondence: jo.adams@bristol.ac.uk; taina.pihlajaniemi@oulu.fi

${ }^{2}$ School of Biochemistry, University of Bristol, Biomedical Sciences Building,

University Walk, Bristol BS8 1TD, UK

${ }^{1}$ Centre of Excellence in Cell-Extracellular Matrix Research, Faculty of

Biochemistry and Molecular Medicine, Biocenter Oulu, University of Oulu,

Aapistie 5, Oulu FIN 90014, Finland
}

\section{Ciomed Central}

(c) 2015 Tu et al. Open Access This article is distributed under the terms of the Creative Commons Attribution 4.0 International License (http://creativecommons.org/licenses/by/4.0/), which permits unrestricted use, distribution, and reproduction in any medium, provided you give appropriate credit to the original author(s) and the source, provide a link to the Creative Commons license, and indicate if changes were made. The Creative Commons Public Domain Dedication waiver (http:// creativecommons.org/publicdomain/zero/1.0/) applies to the data made available in this article, unless otherwise stated. 
(Continued from previous page)

Conclusions: Through identification of MACITs in multiple metazoan phyla we developed a model for the evolution of MACITs. The experimental data demonstrate conservation of MACIT molecular and cellular properties and tissue localisations in the invertebrate, C. elegans.

Keywords: Collagen, MACIT, Molecular phylogeny, Genome paralogy, Neuromuscular junction

\section{Background}

The extracellular matrix (ECM) of metazoans is an intricate, proteinaceous meshwork that underlies all epithelia and endothelia, and surrounds all connective tissue cells. It promotes cell adhesion, migration, differentiation and proliferation, and provides a supporting structure to which cells adhere. The complete genome sequences of multiple metazoans and especially domain arrangement studies have revealed the conservation and diversity of ECM proteins in metazoans $[1,2]$.

Collagens are one of the major classes of ECM macromolecules with multiple functions in the constitution and maintenance of the ECM of most animals [3]. Among the 28 collagen types known in mammals, collagens XIII, XXIII and XXV form a subgroup of structurally related collagens that have, so far, been studied only in mammals. These collagens, named here as MACITs (Membrane-
Associated Collagens with Interrupted Triple-helices), are type II transmembrane proteins, composed of a short Nterminal cytosolic domain, a transmembrane domain and three collagenous domains (COL1-COL3), flanked and interrupted by non-collagenous sequences (NC1-NC4) (Fig. 1a) [4-6]. The ectodomains of the three collagens can be shed by furin convertases $[5,7,8]$. While the physiological functions and molecular mechanisms of MACIT collagens are not fully known, studies with genetically-engineered mouse models have suggested requirements for collagen XIII in the maturation of neuromuscular junctions (NMJ) $[9,10]$ and for collagen XXV in the development of the NMJ and the survival of motor neurons [11]. Moreover, collagen XXIII is up-regulated in human prostate and head and neck cancer progression [12-14] and collagen XXV is involved in amyloid $\beta$ fibril aggregation and the formation of protease-resistant
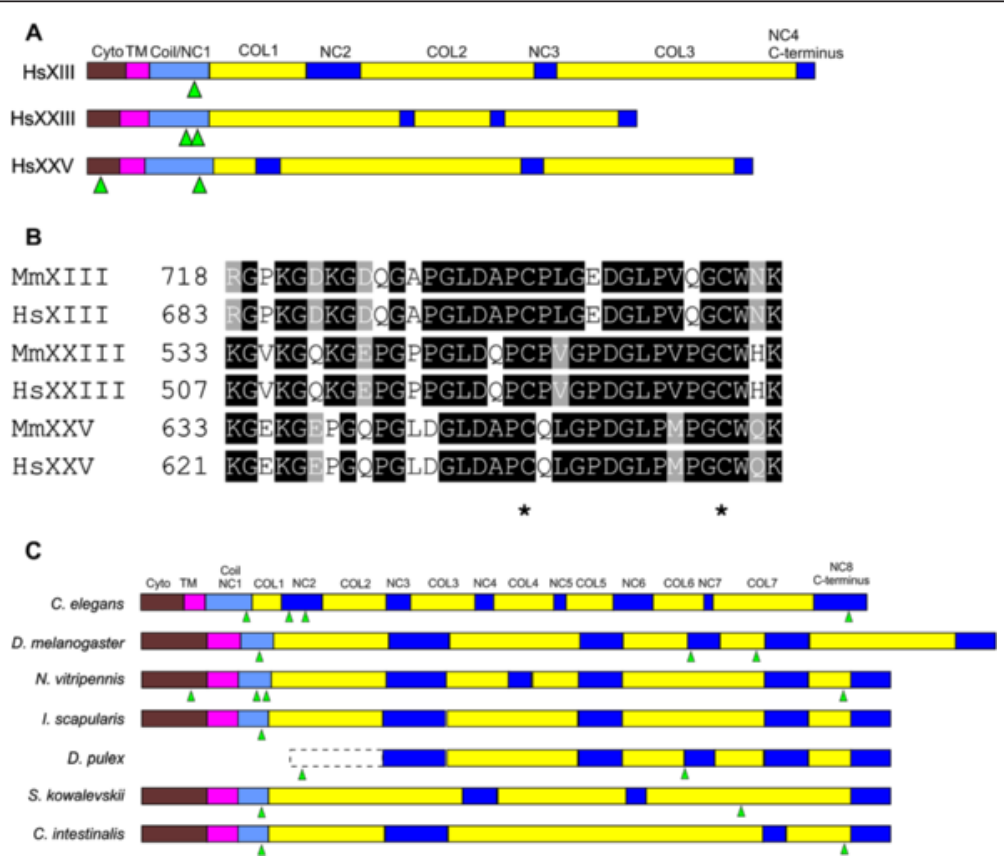

Fig. 1 Domain architecture of MACIT collagens and conservation of the C-terminus. a Schematic diagrams of the domain organization of mammalian collagens XIII, XXIII and XXV, drawn to scale for the polypeptide lengths. b Multiple sequence alignment (MSA) of the C-termini of human and mouse MACITs. Black shading indicates residues conserved in more than $50 \%$ of the sequences, grey shading indicates semi-conserved residues, white indicates non-conserved residues. Numbers refer to the starting amino acid position. Conserved cysteine residues are indicated with asterisks. c Schematic diagrams of the domain organization of MACIT collagens from invertebrates. In (a) and (c), collagenous (COL) domains are shown in yellow, non-collagenous (NC) regions in dark blue, the NC1 domain composed of coiled-coil sequences (Coil/NC1) in pale blue, the transmembrane domain (TM) in magenta, and the cytosolic domain (Cyto) in brown. Green arrowheads indicate putative furin cleavage sites 
bundles, and therefore may regulate the development and progression of Alzheimer's disease [5].

To complement the still scanty knowledge of the properties and functions of the MACITs in vertebrates we embarked on an investigation of the evolution of these proteins and their possible roles in invertebrates, with an experimental focus on Caenorhabditis elegans. C. elegans has over 150 collagen genes and most of these encode cuticle components, which are structurally similar to the FACIT (Fibril-Associated Collagens with Interrupted Triple-helices) collagens of vertebrates $[15,16]$. There are also other collagen types known in C. elegans, especially those belonging to the metazoan basement membrane toolkit [2]. The collagen IV $\alpha$-chain homologs EMB-9 and LET-2 are detected in the body wall muscle and some somatic cells of the gonad [17]. Mutations of emb-9 or let-2 cause lethality at the two-fold stage of embryogenesis [18]. The collagen XVIII homolog CLE-1 is expressed in body wall muscle and several neuronal subgroups [19]. C. elegans is also a useful model organism for functional analyses, especially of the nervous system, on account of the availability of genetic mutants [20-23] and novel, large scale genomic and proteomic tools [24, 25]. Recombineering-based transgene construction (C. elegans TransgeneOme) using a wellmapped fosmid (large genomic DNA, gDNA) clone library together with loss-of-function mutation rescue technology has provided a broad platform for the in vivo analysis of protein function in this animal $[24,26]$. We report here for the first time that MACITs are widespread but not ubiquituous in bilaterians. We present molecular and phylogenomic analyses of the evolution of the MACIT collagens and demonstrate conservation of molecular, functional and tissue localization properties of C. elegans MACIT.

\section{Results}

Identification of MACIT homologues in many bilaterians

The domain architectures of mammalian collagens XIII, XXIII and XXV are shown in Fig. 1a. Typically, the transmembrane domain is followed extracellularly by a short coiled-coil region which assists in trimerisation [27, 28]. From multiple sequence alignment of human and mouse MACITs, we also noticed that the C-terminal 63 amino acids, especially the last 34 residues, are unusually highly conserved, both in species orthologues, and also between collagens XIII, XXIII and XXV. This sequence conservation includes two characteristically-spaced, completely conserved cysteine residues (asterisks, Fig. 1b). The functional role of this region is unknown. With regard to our goal of searching for MACIT proteins in other metazoans, our criteria for the identification of proteins related to collagens XIII, XXIII and XXV included: a) a predicted type II transmembrane topology; b) the presence of interrupted collagen triple helical regions in the predicted protein ectodomain, and c) sequence conservation of the Cterminal region motif including the cysteine residues.

Sequences of human collagens XIII, XXIII and XXV were used first in systematic BLASTP and TBLASTX searches of the available NCBI genomic, cDNA or transcriptomic resources for birds, reptiles, amphibia, bony and cartilaginous fish, lampreys, urochordates, echinoderms, hemichordates and cephalochordates, protostome phyla, early-diverging metazoans and non-metazoans. Analyses were then expanded and "hits" validated as described in the Methods. This survey greatly expanded the dataset of recognized MACIT sequences and identified MACITs in many phyla in which MACITs were previously unknown. Accession numbers for MACITs from species representative of all the phyla in which MACITs were identified are given in Table 1. MACIT sequences were identified in multiple lineages of bilaterians, but not in any of the earlydiverging metazoan phyla (Ctenophora, Porifera, Placazoa, Cnidaria), or several major protostome phyla (Annelida, Mollusca). Within deuterostomes, MACITs were not identified in the available species of Echinodermata (Stronglyocentrus purpuratus), Cephalochordata (Branchiostoma floridae or Branchiostoma belcheri), or Cyclostomata (Petromyzon marinus and Lethenteron japonicum) (Fig. 2). MACITs were not identified in non-metazoan species.

Within protostomes, single MACIT-encoding genes were identified in C. elegans and multiple other nematodes and in species from all classes of arthropods (Table 1, Fig. 2). In C. elegans the predicted MACIT protein (Fig. 1c), ORF F29C4.8, has been named COL-99 (Putative cuticle collagen 99) (www.wormbase.org). Expression of the gene has been confirmed at the mRNA level, but not proven by protein data [29]. Five alternative splicing variants have been predicted, although as yet without experimental confirmation (www.uniprot.org). We investigate COL-99 more deeply in the experimental sections of the Results.

In D. melanogaster, one predicted MACIT homologue was identified (Table 1 and Fig. 1c). Collagen $\alpha$ chain CG43342 is composed of 822 amino acids including one transmembrane domain close to the $\mathrm{N}$-terminus and four interruptions within the collagenous ectodomain (Fig. 1c). The existence of a protein has not yet been proven but there is evidence at the level of transcription (www.uniprot.org). Four alternatively spliced isoforms have been predicted but these are yet to be confirmed experimentally [30]. In the modENCODE Temporal Expression Profile, peak expression of CG43342 has been detected at the 6-12 $\mathrm{h}$ embryonic stage through microarray studies [30]. Single MACIT-encoding genes were also identified in other Hexapoda (Table 1). The predicted MACITs of T. castaneum, B. impatiens and $N$. vitripennis MACITs are shorter proteins than D. melanogaster 
Table 1 The dataset of MACIT protein sequences from protostomes and deuterostomes analysed in this study. Key: + sequence corrected versus expressed sequence tag

\begin{tabular}{lr}
\hline Phylum/Species/protein name GenBank accession & $\begin{array}{l}\text { Code name in } \\
\text { MSAs and tree }\end{array}$ \\
\hline
\end{tabular}

Nematoda

Caenorhabditis elegans MACIT/Col-99

C briggsae MACIT

NP_499869 $\quad C e$

Arthropoda

Drosophila melanogaster MACIT

Nasonia vitripennis MACIT

Tribolium castaneum MACIT

Ixodes scapularis MACIT

Bombus impatiens MACIT

Daphnia pulex MACIT

(incomplete $\mathrm{N}$-end)

Hemichordata

Saccoglossus kowalevskii MACIT

Urochordata

Ciona intestinalis MACIT

Vertebrata: Fish

Callorhinchus milii XIII

Callorhinchus milii XXIII

Callorhinchus milii XXV

Salmo salar collagen XIII

Danio rerio collagen

XIII (partial)

Danio rerio collagen XXIII

Danio rerio collagen XXV

Maylandia zebra collagen XIII

Takifugu rubripes

collagen XXIII

Takifugu rubripes

collagen XXV

Oryzias latipes collagen XIII

Oreochromis niloticus

collagen XXV

Latimeria Chalumnae

collagen XXIII

Latimeria Chalumnae

collagen XXV

Vertebrata: Amphibians

Xenopus tropicalis

collagen XIII

Xenopus tropicalis

collagen XXV

Vertebrata: Reptiles
Table 1 The dataset of MACIT protein sequences from protostomes and deuterostomes analysed in this study. Key: + sequence corrected versus expressed sequence tag (Continued)

\begin{tabular}{|c|c|c|}
\hline $\begin{array}{l}\text { Anolis carolinensis } \\
\text { collagen XXIII }\end{array}$ & XP_008103145 & AcXXIII \\
\hline $\begin{array}{l}\text { Anolis carolinensis } \\
\text { collagen XXV }\end{array}$ & XP_008110328 & $A c X X V$ \\
\hline $\begin{array}{l}\text { Chrysemys picta bellii } \\
\text { collagen XIII }\end{array}$ & XP_008170226 & CpbXIII \\
\hline $\begin{array}{l}\text { Chrysemys picta bellii } \\
\text { collagen XXIII }\end{array}$ & XP_008164659 & CpbXXIII \\
\hline $\begin{array}{l}\text { Chrysemys picta bellii } \\
\text { collagen XXV }\end{array}$ & XP_008168359 & CpbXXV \\
\hline \multicolumn{3}{|l|}{ Vertebrata: Birds } \\
\hline $\begin{array}{l}\text { Melopsittacus undulatus } \\
\text { collagen XIII }\end{array}$ & $X P_{-} 005153749$ & MuXIII \\
\hline $\begin{array}{l}\text { Taeniopygia guttata } \\
\text { collagen XIII }\end{array}$ & XP_004176296 & $\operatorname{TgXIII}$ \\
\hline Gallus gallus collagen XIII & XP-004942057 & GgXIII \\
\hline Gallus gallus collagen XXIII & XP_003642131 & GgXXIII \\
\hline Gallus gallus collagen XXV & $X P_{-} 427455$ & GgXXV \\
\hline $\begin{array}{l}\text { Pseudopodoces humilis } \\
\text { collagen XXV }\end{array}$ & XP_005518035 & PhXXV \\
\hline \multicolumn{3}{|l|}{ Vertebrata: Mammals } \\
\hline Equus caballus collagen XIII & XP_003363528 & EcXIII \\
\hline Equus caballus collagen XXV & XP_005607984 & EcXXV \\
\hline $\begin{array}{l}\text { Canis lupus familiaris } \\
\text { collagen XXIII }\end{array}$ & XP_005626369 & CIfXXIII \\
\hline Mus musculus collagen XIII & NP_031757 & MmXIII \\
\hline Mus musculus collagen XXIII & NP_700442 & MmXXIII \\
\hline Mus musculus collagen XXV & NP_084114 & $M m X X V$ \\
\hline Ovis aries collagen XIII & XP_004021682 & OaXIII \\
\hline Ovis aries collagen XXIII (partial) & XP_004009451 & OaXXIII \\
\hline Ovis aries collagen XXV & XP_004009675 & OaXXV \\
\hline Homo sapiens collagen XIII & NP_001123575 & HsXIII \\
\hline Homo sapiens collagen XXIII & NP_775736 & HsXXIII \\
\hline Homo sapiens collagen XXV & NP_942014 & HsXXV \\
\hline
\end{tabular}

MACIT (in the range 638-682 residues) but are characterized by the same domain architecture including four interruptions of the collagenous regions (Table 1 and Fig. 1c). MACITs were also identified in other classes of arthropods, as exemplified by the chelicerate, Ixodes scapularis, and the crustacean, D. pulex, both of which contain four collagenous regions (Table 1 and Fig. 1c). The predicted $D$. pulex MACIT lacks cytoplasmic and transmembrane domains and thus the prediction appears to be incomplete at the $\mathrm{N}$-terminal end (Fig. 1c).

Within deuterostomes, single MACIT encoding genes were identified in the hemichordate Saccoglossus 


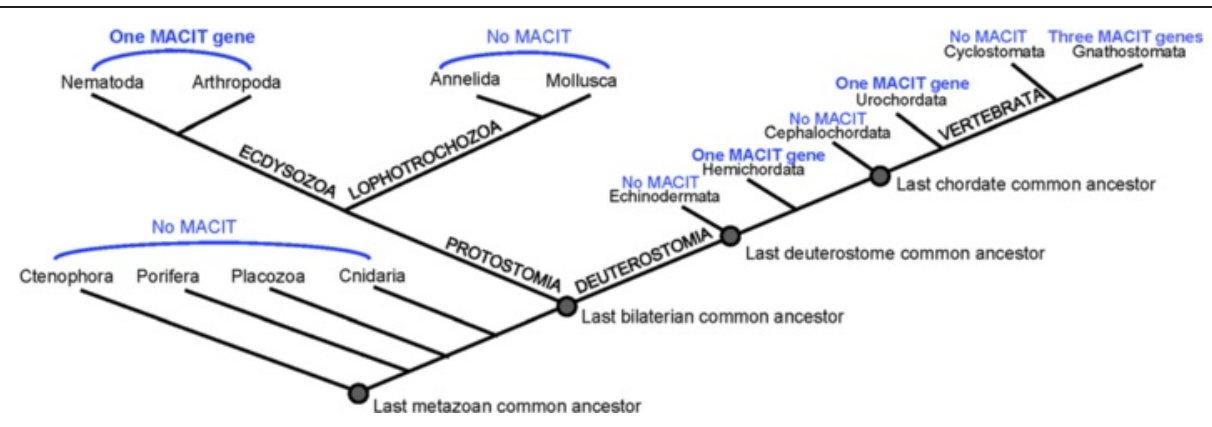

Fig. 2 Schematic of MACIT evolution within the major lineages of the metazoan tree of life. The schematic evolutionary tree of metazoans demonstrates the major lineages of metazoans and the presence or absence of MACIT-encoding sequences identified in this study. The Gnathostomata (jawed vertebrates) are the only lineage in which more than one MACIT gene/genome was identified. Details of representative species in which MACITs were identified are given in Table 1

kowalevskii and the urochordate Ciona intestinalis (Table 1, Fig. 2). The predicted polypeptides are of similar lengths to the mammalian MACITs. S. kowalevskii MACIT includes three collagenous regions and its coiledcoil region is only weakly predicted (residues 60-96, MARCOIL score of 0.2). C. intestinalis MACIT more closely resembles the domain architecture of mammalian collagens XIII, XXIII and XXV and contains three collagenous regions and a well-defined coiled-coil region (residues 73104, MARCOIL score of 1.0) (Fig. 1c).

With regard to the encoding of MACITs in Gnathostomata (jawed vertebrates), no homologues were identified in the two available species of agnathans (jawless vertebrates), the lampreys Petromyzon marinus and Lethenteron japonicum [31, 32] (Fig. 2). This implies that the divergence of this lineage likely involved loss of the MACIT gene. Three predicted proteins corresponding to orthologues of collagens XIII, XXIII and XXV were identified in a cartilaginous fish, the elephant shark Callorhinchus milii [33], and within bony (ray-finned) fish. In contrast, no collagen XIII orthologue was identified in the coelacanth Latimeria chalumnae, a species representative of the lobe-finned fish that are the closest group to the tetrapods [34], although collagen XXIII and XXV orthologues were present. No orthologues of collagen XXIII were identified in the available amphibian species, whereas orthologues to each of collagens XIII, XXIII and XXV were identified in species of reptiles, birds or mammals (Table 1 ).

\section{High conservation of the furin-cleavage sites and C- terminal region of MACITs contrasts with low conservation of the cytoplasmic domain}

Release of the ectodomain by furin proteases is a wellestablished property of mammalian collagens XIII, XXIII and XXV [5-7]. Furin is widely expressed in eukaryotic cells. In C. elegans Furin-like proteinase KPC-1 has important roles in developmental functions [35, 36]. The furin cleavage site prediction software ProP is based on experimental results from the literature and computer data analyses [37]. In our study multiple sequence alignment of the newly identified MACIT sequences in conjunction with ProP prediction of furin cleavage sites for individual sequences identified that furin cleavage sites are also widely present in the MACITs of invertebrates (arrowheads in Fig. 1c). A predicted cleavage site within the $\mathrm{NC} 1$ region adjacent to the transmembrane domain was well-conserved. Variant sequences were identified in the invertebrate MACITs (see below). Unlike the mammalian MACITs, additional cleavage sites were predicted within the ectodomains of many of the invertebrate MACITS (Fig. 1c).

The C-terminal region of MACITs includes triple helical motifs and a final non-collagenous region that are extremely highly conserved across the representative MACITs (Fig. 3). With the exception of C. intestinalis, MACITs from invertebrates typically differ in the Cterminal three amino acids, WKP, WCS, or WRP instead of $\mathrm{W}(\mathrm{H} / \mathrm{N} / \mathrm{Q}) \mathrm{K}$, and the C-terminal domain extends about 30 residues beyond this in the MACITs of invertebrates (shown for C. elegans in Additional file 1). In contrast, the $\mathrm{N}$-terminal regions, corresponding to the cytoplasmic domain, are weakly conserved and aligned poorly when all the MACITs in our dataset were entered in a multiple sequence alignment (unpublished observation). However, when collagen XIII, XXIII and XXV sequences were examined separately as sets of species orthologues, elements of conservation were apparent, although the consensus for collagen XXIII was much weaker than those derived for collagen XIII or XXV (Fig. $4 \mathrm{a}-\mathrm{c}$ ). The cytoplasmic domains of collagens XIII and XXV include one or two conserved cysteine residues close to the transmembrane domain (bold in consensus in Fig. $4 \mathrm{~b}$ and c). Possibly, these residues are targets for palmitoylation [38]. The cytoplasmic domains of invertebrate MACITs are variable in length and show very little sequence conservation. A juxta-membrane cysteine is present in a number of these sequences, although not in 


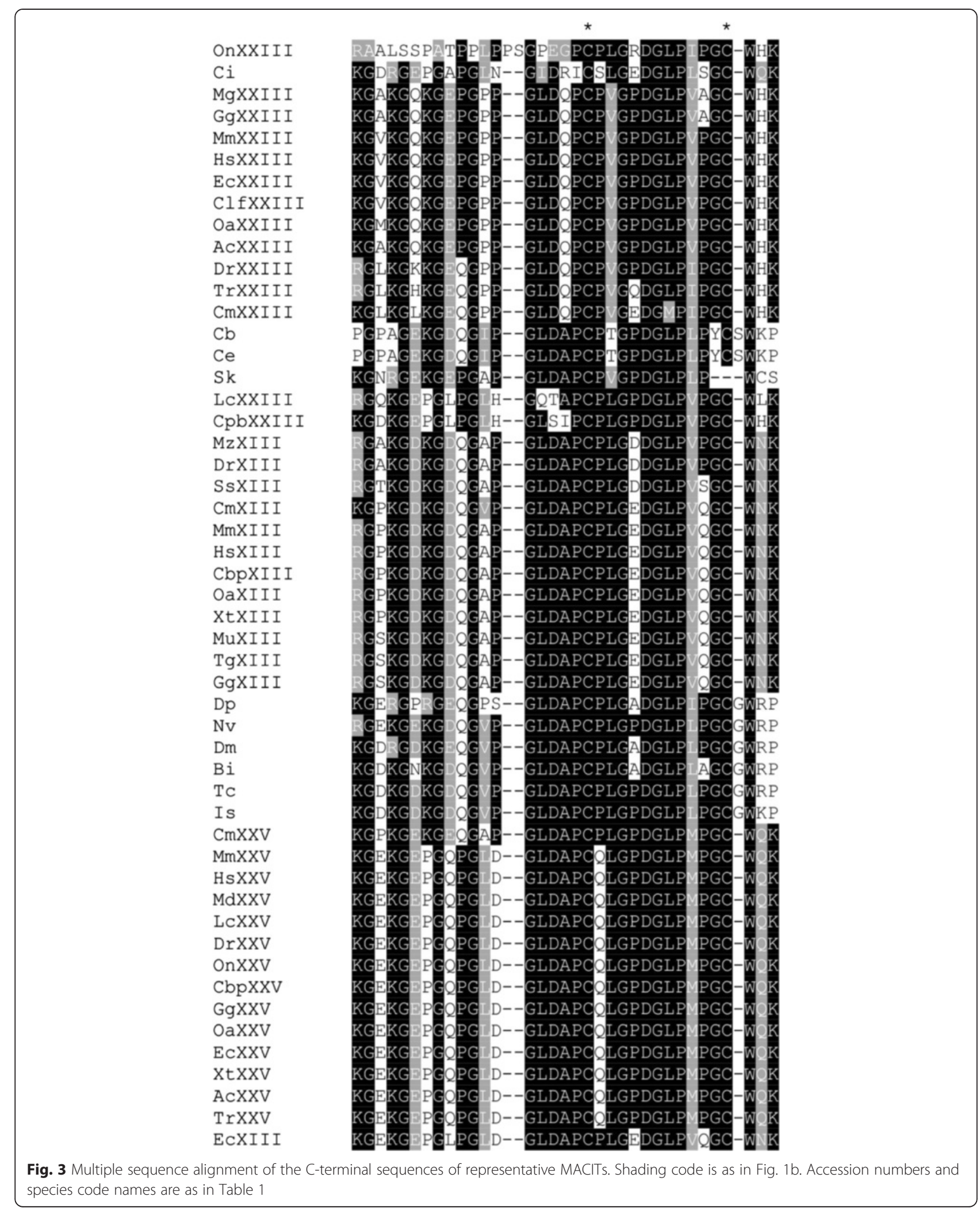




A
TrXXIII
OnXXIII
CmXXIII
DrXXIII
LcXXIII
AcXXIII
CpbXXII
ClfXXIII
MmXXIII
HsXXIII
consensus

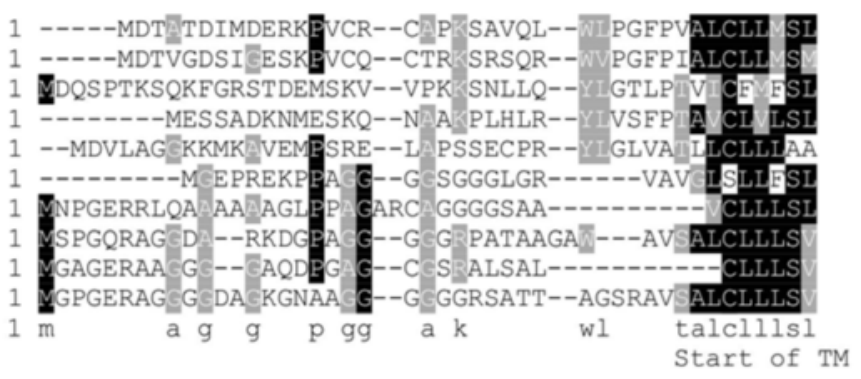

\section{B}

DrXXV

OnXXV

GgXXV

CmXXV

XtXXV

TrXXV

LCXXV

CpbXXV

AcXXV

MdXXV

MmXXV

HsXXV

ECXXV

Oaxxv

consensus

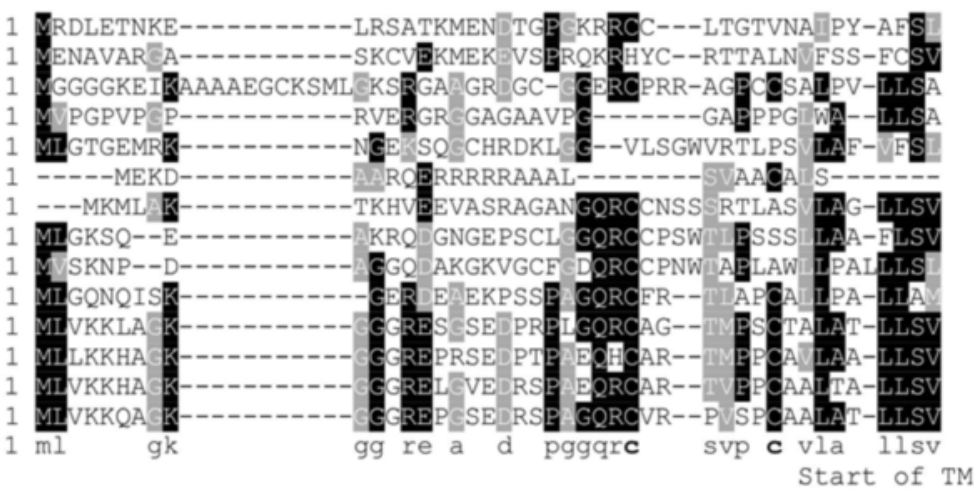

C

MuXIII

TgXIII

GgXIII

DrXIII

OlXIII

ECXIII

HsXIII

OaXIII

MmXIII

XtXIII

SsXIII

MzXIII

consensus

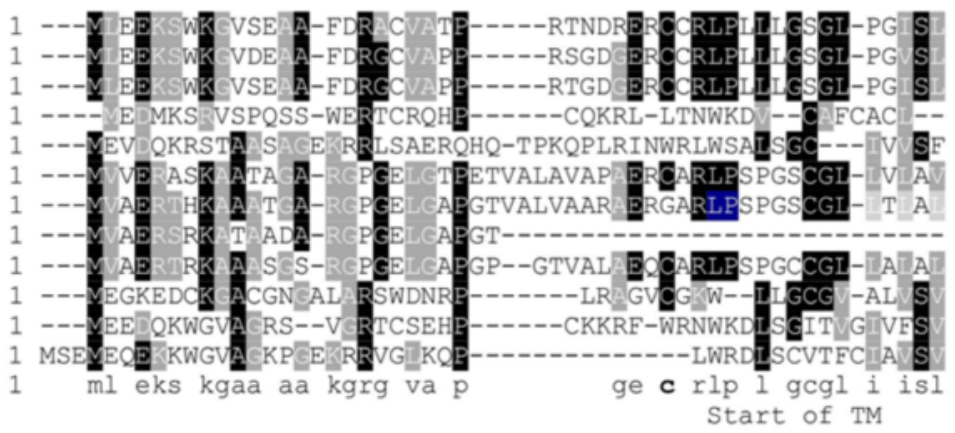

D

$\mathrm{Cb}$

$\mathrm{Sk}$

$\mathrm{Ce}$

Is

$\mathrm{Ci}$

Nv

$\mathrm{Bi}$

Dm

consensus

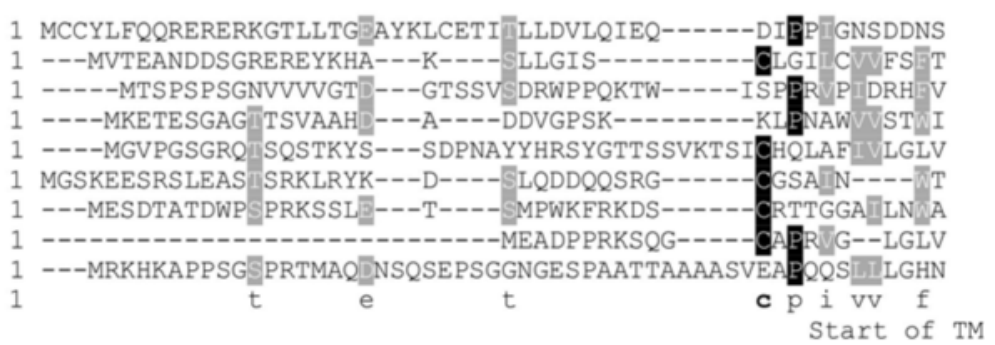

Fig. 4 Multiple sequence alignments of the cytoplasmic domains of representative MACITS. Separate alignments were prepared for collagens XXIII (a), XXV (b), XIII (c), and invertebrate MACITs (d). A consensus sequence (the aa represented in at least $50 \%$ of the sequences) is shown below each set with the conserved cysteines bolded. Shading code is as in Fig. 1b. Species code names are as in Table 1

nematode, D. melanogaster, or I. scapularis MACITs (Fig. 4d).

The evolution of MACITs has involved expansion to a gene family in vertebrates

It is well-established that many gene families of vertebrates consist of paralogous genes that arose during the two rounds of large-scale, en bloc genome duplication that took place early after the divergence of vertebrates; these events are considered to have taken place before the divergence of cartilaginous fish [39, 40]. These events have resulted in the existence of large, paralogous chromosomal regions within the genomes of vertebrates [41] that can be used to derive information on the 
relationships between members of vertebrate gene families. Therefore, we next examined whether COL13A1, COL23A1 and COL25A1 are located within paralogous regions of the human genome. The human genome is suitable for this analysis because the rate of DNA rearrangement is relatively slow [42].

Initial assessment through the database of paralogons in the human genome [43] identified that the chromosomal regions 4q25, 5q35 and 10q22 indeed share blocks of paralogy. Detailed analysis of shared paralogous genes between these regions based on the human reference genome (NCBI assembly GRCh38.p2), identified that, in addition to COL13A1, COL23A1 and COL25A1, genes encoding members of the Sec24 gene family and three members of the ADAMTS gene family are located within each of these chromosomal regions (Fig. 5a). ADAMTS2, -3 and -14 are known members of a wellrecognized ADAMTS sub-family on the basis of their protein sequence characteristics [44]. Support for the paralogy of these chromosomal regions is also provided by the presence of several paralogous gene pairs: for example AGXT2L1 and AGXT2L2 on chromosomes 4 and 5 , respectively, or members of the $D D X$ gene family on chromosomes 5 and 10 (Fig. 5a).

To confirm that these relationships at the level of the genome did indeed represent the results of the en bloc genome duplication early in the vertebrate lineage, we also examined species representative of earlier diverging vertebrates: the chicken, G. gallus, and the freshwater pufferfish, T. nigroviridis, for possible conservation of neighboring genes around the COL13A1, COL23A1 and COL25A1 loci. Conservation of synteny was apparent for the regions around all three genes in the chicken (Fig. 5b). In the pufferfish, COL13A1 is unmapped and genes orthologous to ADAMTS14, DDX50, etc., could not be identified on the same scaffold. Conservation of synteny on chromosome 1 was apparent for the gene neighbours of COL23A1. COL25A1 is unmapped, however, RLP34 and AGXT2L1 are located on the same genomic scaffold, thus demonstrating conservation of synteny for this locus (Fig. 5c). The conservation of synteny across these three lineages confirms that these paralogous regions arose from the two rounds of large-scale genome duplication early in the vertebrate lineage.

Although these data clearly demonstrated that COL13A1, COL23A1 and COL25A1 are located in paralogous regions of vertebrate genomes, the depth of information on paralogous neighbouring genes was not sufficient to distinguish between possible models of the evolutionary relationships between COL13A1, COL23A1 and COL25A1 with reference to the two rounds of genome duplication. Therefore, molecular phylogenetic studies of protein sequence relationships were undertaken.

\section{Molecular phylogeny of MACIT proteins}

To develop a clear model of the evolution of the MACIT gene family in vertebrates, we next analysed their molecular phylogeny on the basis of their protein sequences. In initial tree-building tests, $C$. intestinalis and S. kowlevskii MACITs consistently grouped with the arthropod MACITs, likely due to long-branch attraction, and destablised the trees. Therefore, these two sequences were not included in the final dataset for tree-building (unpublished observation). Further tests consistently demonstrated very similar topologies for trees based on multiple sequence alignments prepared in webPRANKS [45] or MUSCLE [46]. Only the webPRANK-based results, that consistently had better statistical support, are shown here. The rooted tree based on 49 MACIT sequences and rendered from phylogenetic inference analysis and treebuilding with the maximum-likelihood method, PhyML, demonstrated that the MACITs of invertebrates form a clade separate from collagens XIII, XXIII or XXV, and also identified that collagen XXIII and XXV are more closely related to each other than to collagen XIII. The root of the tree was placed between the invertebrate MACITs and the MACITs of vertebrates (Fig. 5d).

\section{C. elegans MACIT mRNA undergoes extensive alternative splicing}

Because C. elegans is a well-established invertebrate model for developmental and functional studies of the neuronal system [22] and with regard to the novel possibility to study protein expression and function in a metazoan with a single MACIT gene, this species was chosen for experimental studies. To confirm the predicted protein sequence data the protein coding region of the col-99 gene was cloned using PCR on synthesized cDNA produced by reverse transcription of mRNA. The full-length nucleotide sequence was obtained by DNA sequencing and the predicted amino acid sequence was compared with other available COL-99 sequences in the $C$. elegans database (www.wormbase.org) (Additional file 1). It should be noticed that the five COL-99 isoforms in the database are only in part confirmed by high-throughput RNA-seq in the modENCODE project for integrative analysis of the $C$. elegans genome [29]. The complete cDNA sequences for these isoforms have not been determined experimentally. All the clones acquired from the cDNA cloning in the current study were of a new type, named as COL-99f (BankIt1764273 col-99 KM875546). We determined that COL-99a lacks exon 4, COL-99c lacks exons 4 and 8, COL-99d lacks exons 4 and 12, COL-99e lacks exons 4 and 16, and the newly identified COL-99f lacks exons 4, 12 , 16. A schematic diagram for the six isoforms is presented in Additional file 2. 


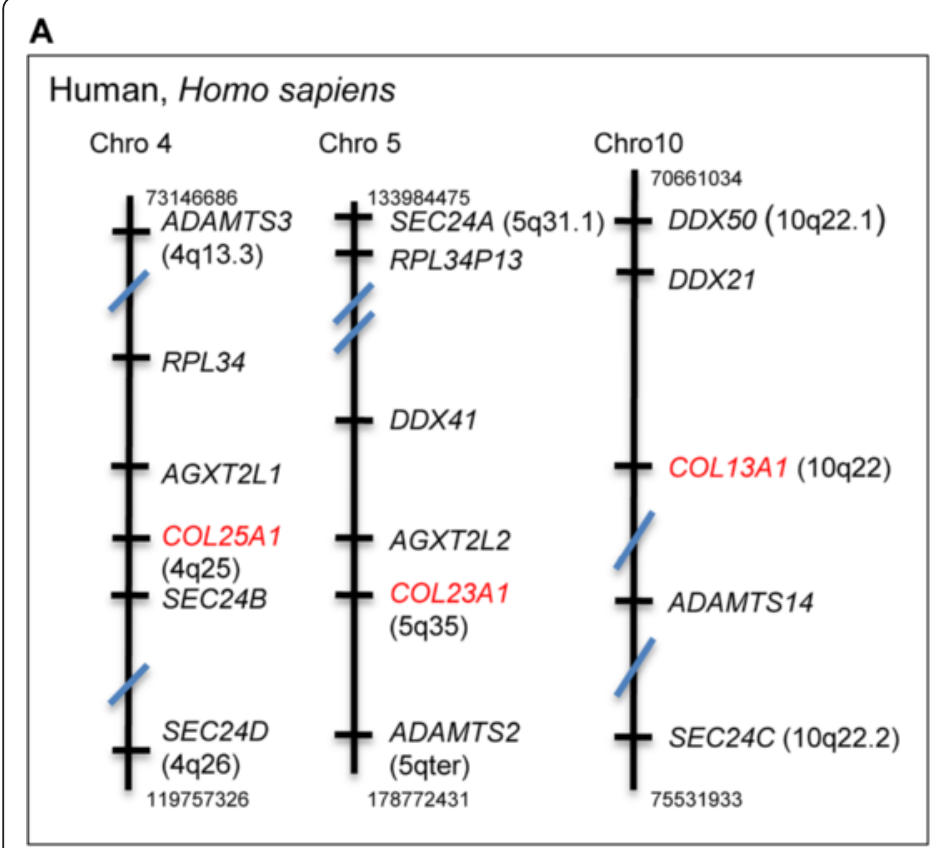

B

\section{Chicken, Gallus gallus}

$\begin{array}{lll}\text { Chro } 4 & \text { Chro } 13 & \text { Chro } 6\end{array}$

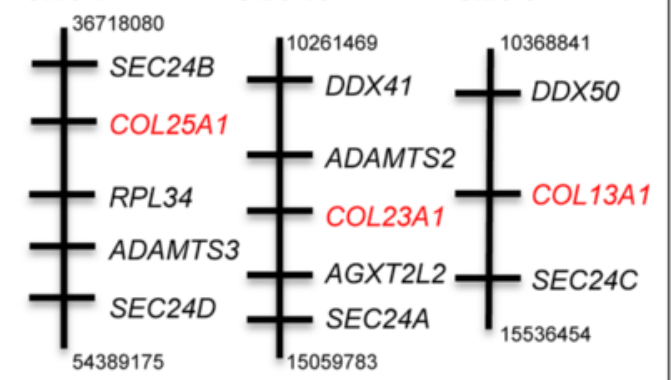

C

Freshwater pufferfish, Tetraodon nigroviridis Chro 1
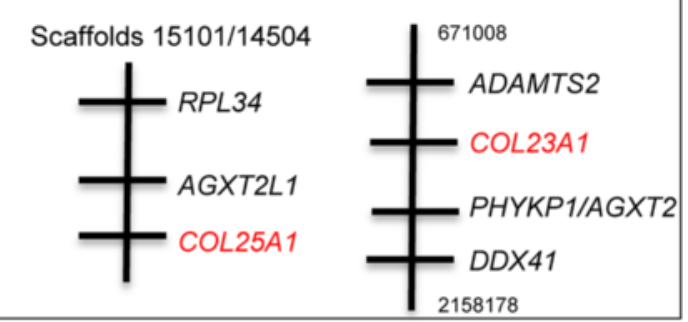

D

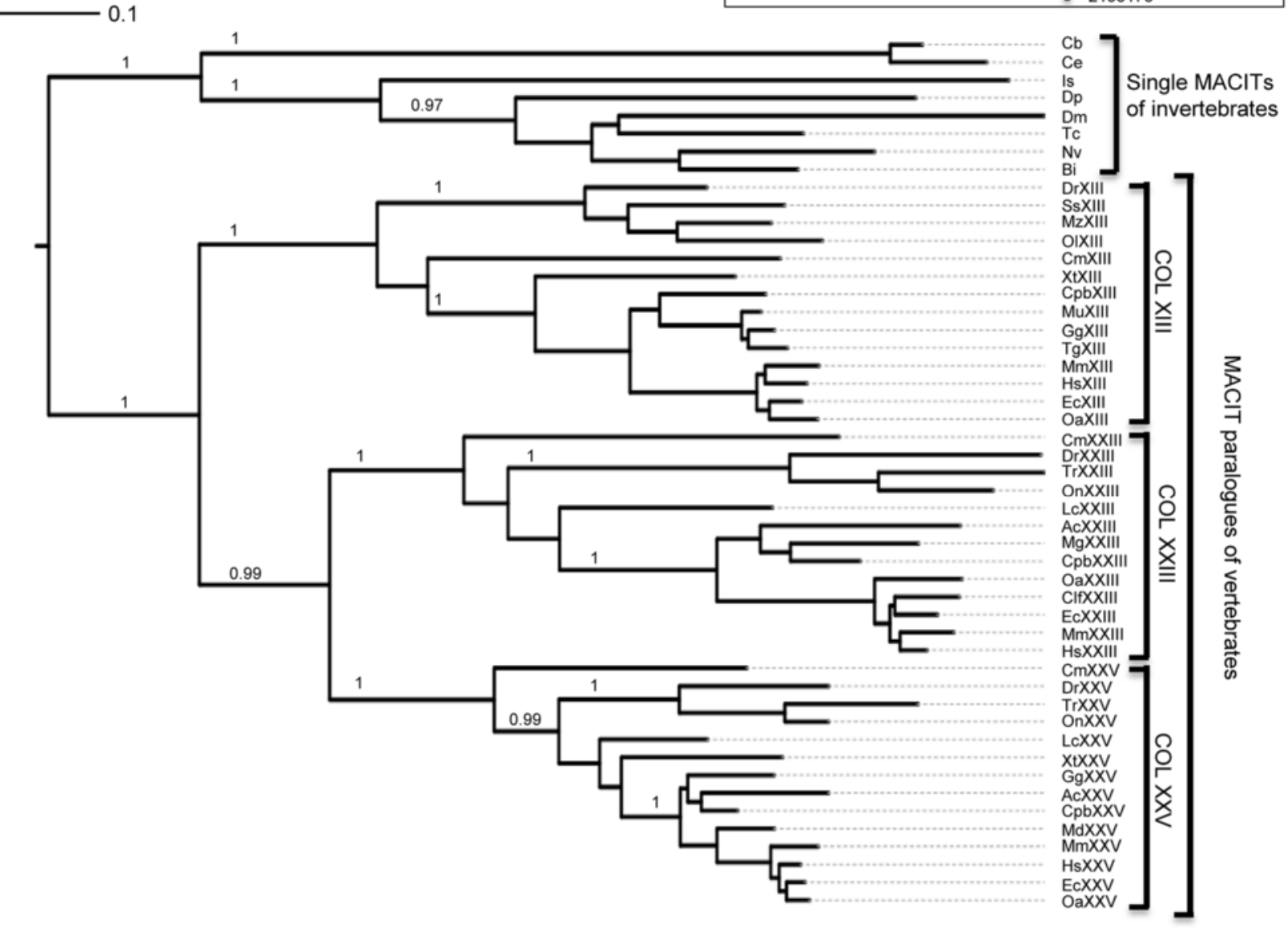

Fig. 5 (See legend on next page.) 
(See figure on previous page.)

Fig. 5 Phylogenomic analyses of the MACITS. COL13A1, COL23A1 and COL25A1 are located in paralogous regions of the human (a), chicken (b), and freshwater pufferfish (c), genomes. In $\mathbf{a}-\mathbf{c}$, each stick diagram represents the region of the chromosome in the vicinity of the relevant MACIT gene and each horizontal line represents a gene; for simplicity of presentation, only the conserved syntenic genes have been included. Numbers above and below each diagram refer to the start and end positions of the first and last genes presented, respectively, on the chromosome in bases. In (c), T. nigroviridis COL25A1 is unmapped in the genome, but is located within the same two over-lapping scaffolds as two of the genes that are syntenic in human and chicken. d, Phylogenetic relationships of MACIT proteins. Bootstrap values above 0.95 are taken to indicate stability of a branchpoint and are shown for the major nodes. Scale bar indicates substitutions/site. Species code names in (d) are as in Table 1

\section{Furin-mediated shedding is a conserved property of $C$. elegans COL-99}

The C. elegans MACIT COL-99 variants are characterized by 7 interrupted collagenous domains (Additional file 1; Fig. 1c). Moreover, there are four putative furinlike protease cleavage sites with a consensus motif RXXR. The cleavage prediction scores calculated with the software ProP differ between RRVR ${ }^{104}$ (0.353), $\operatorname{RRPR}^{137}$ (0.132) RKMR ${ }^{153}$ (0.470), and RRKR ${ }^{648}$ (0.556). $\mathrm{RRVR}^{104}$ is located in the first, $\mathrm{NC1}$, non-collagenous domain corresponding to a cleavage site that is widely conserved (Fig. 1c), but $\mathrm{RKMR}^{153}$ is predicted as a more likely furin cleavage site. The $\mathrm{C}$-terminal putative cleavage site $\left(R R K R^{648}\right)$ is not present in mammalian MACITs (Additional file 1 and Fig. 1a, c). It is noticeable that in human collagen XIII the single furin cleavage site, RRRR ${ }^{107}$, has a prediction score of 0.649 . This cleavage site has been confirmed in our previous study of recombinant collagen XIII expressed in insect cells [7]. In human collagen XXIII, there are two putative furin cleavage sites $\operatorname{RLLR}^{97}$ and RTAR ${ }^{110}$ in the NC1 domain, both with relatively low cleavage prediction scores of 0.285 and 0.315 , respectively. In human collagen $\mathrm{XXV}$, one site, REPR ${ }^{16}$, with a score of 0.511 is located in the cytosolic domain, whereas another site, RIAR ${ }^{112}$, is located within the NC1 domain, but with a lower score of 0.328. C. elegans MACIT contains 7 cysteines, of which the positions of two in the $\mathrm{NC} 1$ domain and two in the NC8 domain are conserved with mammalian MACITs (Fig. 6a). Cysteines in the transmembrane domain and the central non-collagenous portion have similar positions to mammalian MACITs (Additional file 1).

To study the biochemical characteristics of the COL99 protein we expressed it as a recombinant protein in mammalian $\mathrm{CHO}$ cells. Using as a template RNA extracted from the worm line col-99::egfp::flag (for details

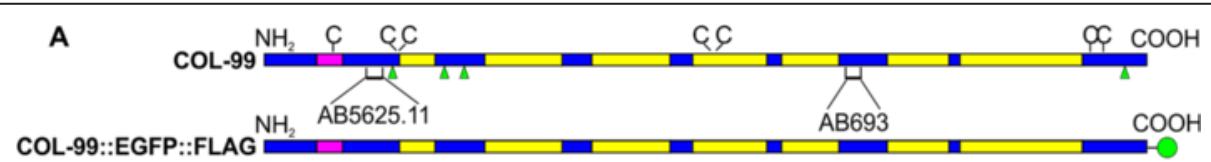

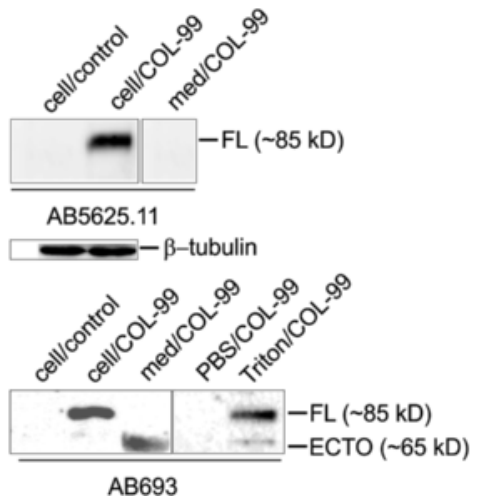

C

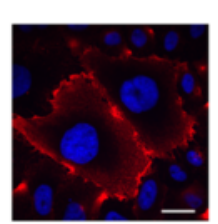

D

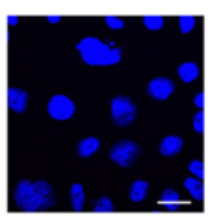

E

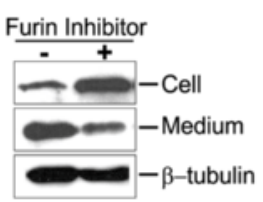

Fig. 6 Characterization of the MACIT protein COL-99 of C. elegans. a Schematic structure of the COL-99 and COL-99::EGFP:.FLAG polypeptides. The domain structure is presented as in Fig. 1 and cysteines (c) are also indicated. The regions used as antigens for the antibodies AB5625.11 and AB693 are marked. The C-terminal tag of COL-99::EGFP::FLAG is shown as a green circle. $\mathbf{b}$ Western blot analysis of subcellular localization of recombinant COL-99 in $\mathrm{CHO}$ cells. From the left to right: control lysate, total lysate of $\mathrm{CHO}$ cells expressing recombinant COL-99, concentrated medium sample, in the upper and lower panels detected with antibody AB5625.11 (upper) or AB693 (lower); and additional PBS-soluble proteins, and Triton X-100-extracted protein fraction from CHO cells expressing COL-99 in the lower panel only detected with AB693. c Immunofluorescent staining of $\mathrm{CHO}$ cells expressing COL-99. The signal was detected by antibody AB5625.11 and secondary anti-rabbit lgG conjugated with AlexaFluor 594. d Control staining with the secondary antibody only. Bars, $20 \mu \mathrm{m}$. e Inhibition of COL-99 ectodomain shedding by Furin Inhibitor I. Right lane, COL-99 expressing CHO cell cultures treated with 2 mM Furin Inhibitor I. Left lane, cells treated with an equivalent volume of methanol as solvent control. $\beta$-tubulin was used as a loading control in (b) and (e) 
on the worm line, see the section Expression of col-99 in C. elegans is highest at the L1-L2 larvae stages of development), we cloned the col-99 cDNA (without the EGFP and FLAG tags as in the fosmid these were codonoptimized for C. elegans gene expression), into a mammalian cell expression vector, which then was used to transfect $\mathrm{CHO}$ cells. For detection of COL-99 protein, two new antibodies against COL-99 protein were generated: the first antibody, termed AB5625.11, being raised against a peptide in the $\mathrm{NC1}$ domain before the predicted furin cleavage site, and the second antibody, AB693, against a peptide located in the predicted ectodomain region (Fig. 6a). In western blots of whole cell extracts under a reducing condition, the antibody AB5625.11 detected a band of $85 \mathrm{kDa}$ in $\mathrm{CHO}$ cells expressing COL-99, whereas control $\mathrm{CHO}$ cells expressing EGFP gave no signal (Fig. 6b). This band can be expected to represent monomeric (single-chain) full-length COL-99, because a furin-based proteolytic cleavage fragment would correspond to a small $\mathrm{N}$-terminal peptide $(\sim 17 \mathrm{kD})$ detected by AB5625.11. Moreover, no signal was seen in the medium with this antibody, demonstrating that the full-length molecules are retained in the cell fraction due to the transmembrane domain (Fig. 6b). Next, western blotting with antibody AB693 was performed, because this antibody should make it possible to identify both full-length and shed molecules. Indeed, the antibody $\mathrm{AB} 693$ identified a band of $85 \mathrm{kDa}$ in the lysates of COL-99-expressing CHO cells, as also seen with AB5625.11. In addition, a band of $\sim 65 \mathrm{kDa}$ was detected in the corresponding medium (Fig. 6b), suggesting cleavage at the $\mathrm{N}$-terminal furin sites. In a further experimental design, the proteins in the COL-99-expressing $\mathrm{CHO}$ cells were extracted sequentially by PBS, and then PBS containing $1 \%$ Triton X-100. Only the latter treatment resulted in extraction of the COL-99 protein (Fig. 6b), the majority of which corresponded to the full-length protein and only minor amounts to the shed form, characteristic of a membrane-associated protein. This need for detergent-based extraction of the cell-associated collagen XIII protein was also reported for mammalian MACIT collagens [7]. The cell membrane location of COL-99 was also defined by immunofluorescence staining of $\mathrm{CHO}$ cells stably transfected with the plasmid encoding col-99 (Fig. 6c \& d).

According to the molecular mass difference of the full-length and the shed forms of COL-99 (Fig. 6b) and the PrOP 1.0 scores of predicted furin cleavage sites, COL-99 can potentially be shed by furin cleavage at $\mathrm{RRVR}^{104} / \mathrm{RKMR}^{153}$ and $\mathrm{RRKR}^{648}$, resulting in an ectodomain composed of 544 or 495 amino acids starting from $\mathrm{N}^{105}$ or $\mathrm{A}^{154}$, respectively, to $\mathrm{R}^{648}$ (Additional file 1 and Fig. 6b). Indeed, addition of Furin Inhibitor I to the culture medium of $\mathrm{CHO}$ cells expressing COL-99 resulted in a clear reduction in the level of COL-99 in the culture medium ( $\sim 70 \%)$, while the COL-99 signal in the cell fraction was reciprocally elevated (Fig. 6e). While the data demonstrate furin cleavage at one or more of the $\mathrm{N}$-terminal sites, use of the less conserved C-terminal site, present in C. elegans and other non-vertebrate MACITs, remains to be proven.

\section{Expression of col-99 in C. elegans is highest at the L1-L2 larvae stages of development}

We next used the fosmid-based C. elegans line col99::egfp::flag to study the expression and localization of COL-99 protein localization in the animals, on the basis that the fosmid-based expression is likely close to the native condition [24]. The col-99-bearing fosmid gene construct col-99::egfp::flag was used to generate transgenic C. elegans lines. From two separate gene transfers we obtained three lines with stable genomic integration. To test the construction strategy we also performed ballistic transformation of another fosmid encoding the $C$. elegans integrin gene, pat-3 (ZK1058.2, WormBase ID is WBGene00003930), chosen as a positive control because data on PAT-3 protein localization in body muscle by antibody staining is available [47].

Fosmid-based gene transcription was confirmed by rescue of an unc-119 loss-of-function mutation in the C. elegans strain HT1593 (called here the unc-119 line and used here as a control) and by RT-PCR using primers specific for fosmid-based transcripts. All three col-99::egfp::flag lines showed the correct size of a DNA fragment from the EGFP CDNA by RT-PCR, and one of the strains was selected for further analysis (Fig. 7a). RNA expression analysis revealed endogenous col-99 transcripts in the unc-119 line and a more prominent band in the new col-99::egfp::flag line, suggestive of a higher expression level when the transgene augments the endogenous expression (Fig. 7a). In western blot analysis of nematode lysates, the fusion protein COL99::EGFP::FLAG showed a molecular mass of $120 \mathrm{kD}$, that is remarkably similar to that of the recombinant human collagen XIII-EGFP fusion protein expressed in $\mathrm{CHO}$ cells (Fig. 7b). Moreover, under non-reducing conditions, the protein COL-99::EGFP::FLAG was detected as a trimer (Fig. 7c). Antibodies to either the GFP- or the FLAG- tag were able to detect the fusion protein in col-99::egfp::flag worm lysates, but the anti-FLAG monoclonal antibody showed a more specific signal (Additional file 3). It should be noted that in the construction of col-99::egfp::flag the tag part including the EGFP, FLAG and the linker peptides accounts for a molecular mass of $35 \mathrm{kD}$.

The adult worms showed very weak col-99 expression (Fig. $7 \mathrm{~d}, \mathrm{f}$ and $\mathrm{h}$ ) in vivo compared to the pat-3::egfp::flag line (Additional file 4). The weak fluorescent signals were detected only in some locations at the body wall (Fig. 7d) and the mouth (Fig. 7f). These signals often 


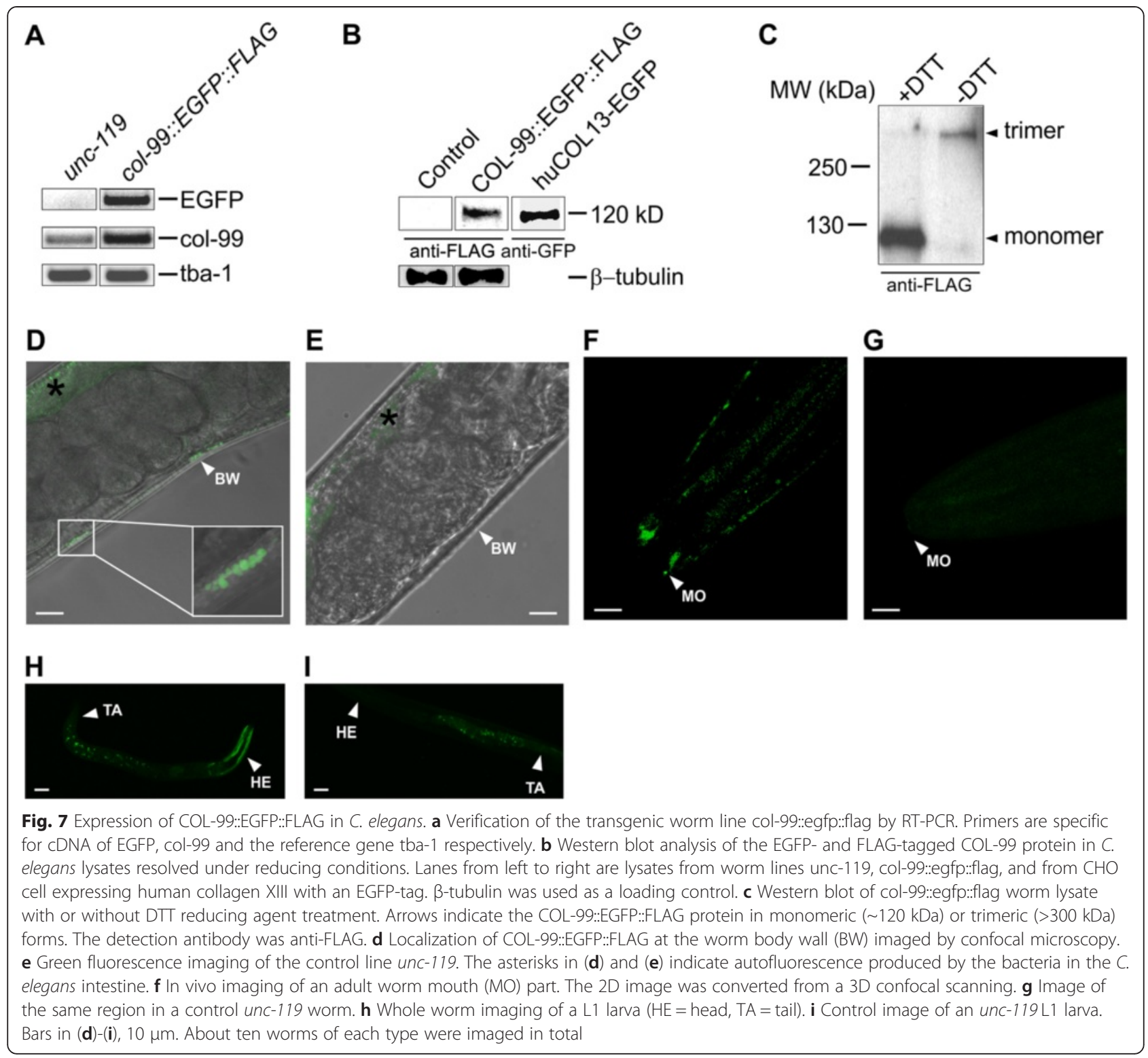

occurred in clusters. The control line unc-119 was negative in the direct EGFP fluorescence imaging (Fig. 7e and g), except for green auto-fluorescent signals in the intestine that are derived from the E. coli food and are seen in both the col-99 transgenic and the unc-119 line (asterisks in Fig. 7d and e). Interestingly, the head part did show prominent signals in younger worms, especially in L1-L2 larvae (Fig. 7h). This signal was specific to the col-99::egfp::flag line (Fig. 7i).

\section{Col-99 is expressed in the C. elegans neuronal and muscle systems}

To obtain more detailed data on COL-99 localization, we performed whole mount immunofluorescence staining of the col-99::egfp::flag worms at different developmental stages, using both methanol/acetone and PFA fixation methods. With anti-GFP staining, COL-99::EGFP::FLAG was detected as spots or clusters in pharyngeal muscle or brain sites in methanol/acetone-fixed specimens (Fig. 8a) whereas the unc-119 control line was negative (Fig. 8b). In PFA-fixed specimens, COL-99 was also detected in the middle body (Fig. 8c) and in the tail (Fig. 8e), whereas the control unc-119 line was negative at these tissue sites (Fig. 8d and f).

We next compared the COL-99::EGFP::FLAG signals with different molecular markers for muscles or neurons. A spot-like appearance of COL-99::EGFP::FLAG was detected by immunofluorescent staining with antiGFP and this was adjacent to the body muscle marker myosin in L1-L2 larvae (magenta in Fig. 8g), suggesting 

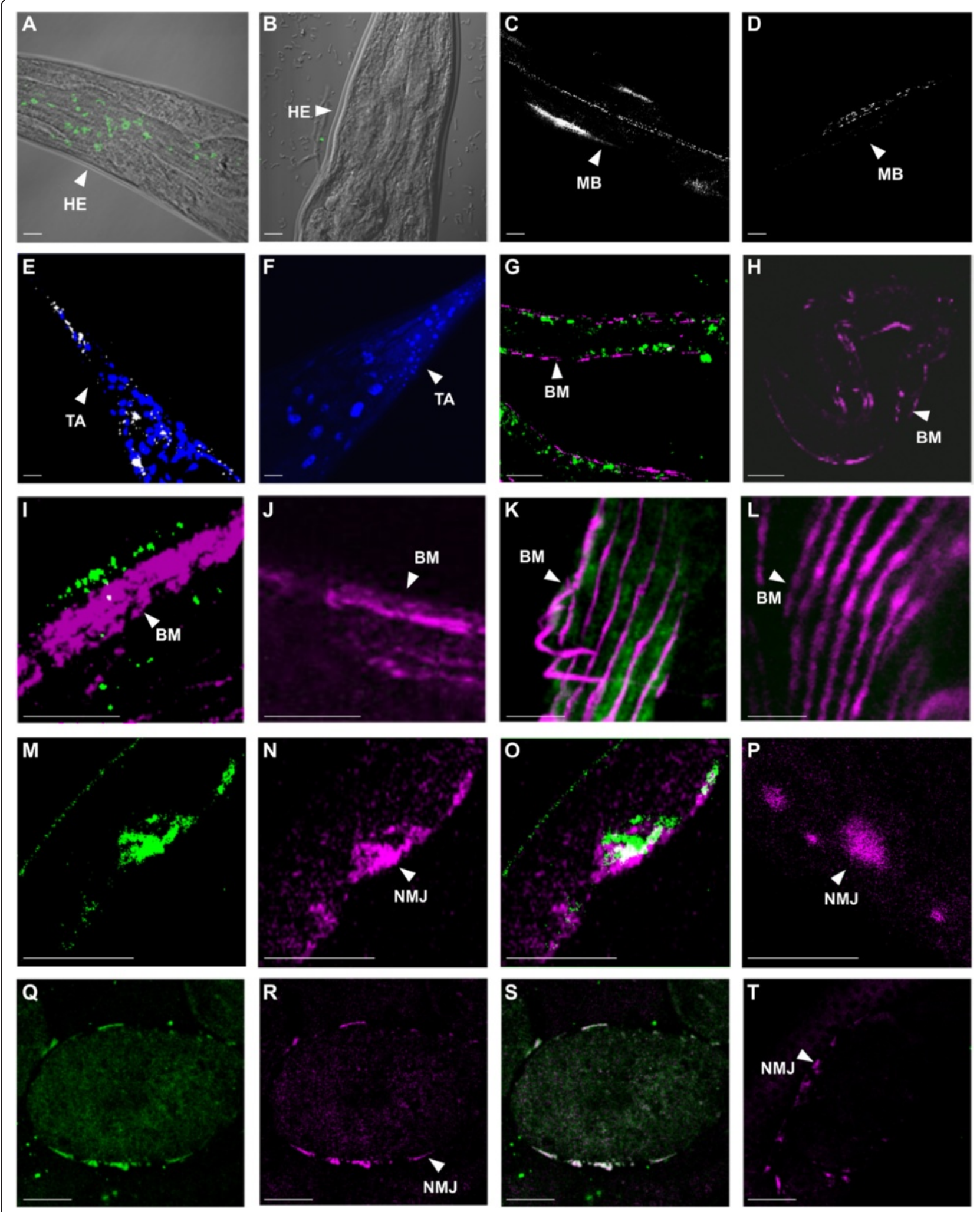

Fig. 8 (See legend on next page.) 
(See figure on previous page.)

Fig. 8 Localization of COL-99::EGFP::FLAG at NMJs and in other tissues. a Detection of COL-99::EGFP::FLAG expression in the head part of an adult C. elegans. Whole mount immunofluorescence staining was performed with a rabbit anti-GFP antibody and AlexaFluor 488-conjugated anti-rabbit IgG. c Detection of COL-99::EGFP::FLAG in the middle body part. The specimen was prepared by a freeze-crack treatment and a mild PFA fixation. The detection antibody was rabbit anti-GFP. e Staining of methanol/acetone fixed tail (TA) section of a col-99::egfp::flag worm with rabbit anti-GFP (white) and DAPI (blue). The green fluorescence detected with AlexaFluor 488-conjugated secondary antibody was converted to white to enhance the sensitivity. $\mathbf{g}$ Double staining of an L1 larva with rabbit anti-GFP (green) and mouse anti-myosin (magenta). The image was converted from a 3D Z-scan and signal was adjusted by Image J software. i Whole-mount immunofluorescent staining of a col-99::egfp::flag adult worm with rabbit anti-GFP (green) and mouse anti-myosin (magenta). $\mathbf{k}$ Immunofluorescent staining of a freeze-crack section of worm muscle after mild PFA fixation with rabbit anti-GFP (green) and mouse anti-myosin (magenta). m-o Immunofluorescent staining of a col-99::egfp::flag worm after freezecrack treatment with rabbit anti-GFP (green in $\mathbf{m}$ and $\mathbf{o}$ ) and a-bungarotoxin (magenta in $\mathbf{n}$ and $\mathbf{o}$ ) showing NMJ localization. $\mathbf{o}$ Merged from $(\mathbf{m})$ and $(\mathbf{n})$. $\mathbf{q}$-s Immunofluorescent staining of col-99 embryos with rabbit anti-GFP (green in $\mathbf{q}$ and $\mathbf{s}$ ) and a-bungarotoxin (magenta in $\mathbf{r}$ and $\mathbf{s})$. $\mathbf{b}, \mathbf{d}, \mathbf{f}, \mathbf{h}, \mathbf{j}, \mathbf{l}, \mathbf{p}$, and $\mathbf{t}$ are negative control staining of unc-119 worms for (a), (c), (e), (g), (i), (k), (o), and (s) respectively. Bars, $5 \mu \mathrm{m}$ in $\mathbf{a}-\mathbf{h}, \mathbf{k}-\mathbf{I}$ and $\mathbf{m}-\mathbf{p}, 10 \mu \mathrm{m}$ in $\mathbf{i}-\mathbf{j}$, and $20 \mu \mathrm{m}$ in $\mathbf{q}-\mathbf{t}$. HE, head; MB, middle body; TA, tail; BM, body muscle; NMJ,

neuromuscular junction

that COL-99::EGFP::FLAG associates with motor neurons. As expected, the control line was negative for GFP staining (Fig. 8h). In adult worms, spot-clustered staining of COL-99::EGFP::FLAG (green) was detected weakly on the body wall along the muscle fibers (magenta) (Fig. 8i) and was specific to the transgenic line (Fig. 8j shows the unc-119 line). However, the overall number of COL-99::EGFP::FLAG-positive sites was lower than in the larvae. Weak expression of COL99::EGFP::FLAG (green) in body muscle was detected in a sagittal freeze-cracked section after mild, short fixation with PFA, but this staining did not co-localize with the muscle marker myosin (magenta) (Fig. 8k). This COL-99 staining was specific because it was not detected in the control line unc-119 (Fig. 8l). However, clear colocalization of COL-99::EGFP::FLAG (green) and the NMJ marker $\alpha$-bungarotoxin (magenta) was observed in the body muscle of adult worms (Fig. 8m-o) and in latestage embryos (Fig. 8q-s). No COL-99::EGFP::FLAG staining was detected in the respective unc-119 negative controls (Fig. 8p and t).

\section{Discussion}

Our investigations of MACIT proteins demonstrate for the first time the extent of the MACIT family in bilaterian animals. The collection of a large dataset of protein sequences has enabled an in-depth analysis of conserved features of this unique sub-family of transmembranous collagens. With new tools and antibodies for C. elegans MACIT, we have made novel observations on the conservation of functional properties between this MACIT from invertebrates and the mammalian MACIT family.

Overall, the phylogenetic distribution of MACITs in extant species leads to the inference that a MACITencoding gene originated in the last common bilaterian ancestor, but has been lost from multiple lineages within both protostomes and deuterostomes. Secreted forms of collagens, exemplified by the fibrillar collagens, are present throughout all metazoans [48], thus the simplest inference is that MACIT collagens evolved far later than secreted collagens. The data on conservation of paralogous locations of COL13A1, COL23A1 and COL25A1 in the human, chicken and freshwater pufferfish genomes support the model that the MACIT gene family of vertebrates debuted during the en-bloc genomic duplications early in the evolution of vertebrates. Because only three MACIT genes are present in modern vertebrates, the data imply that a fourth paralogon resulting from the second round of duplication was lost early in the divergence of vertebrates. Additional gene losses appear to have occurred subsequently in some vertebrate lineages. Whereas orthologues of collagen XXV were identified in all classes of vertebrates, collagen XIII appears to have been lost in the lobe-finned fish lineage and collagen XXIII to have been lost from the available amphibian species. Information on additional species of lobe-finned fish or amphibians would be needed to substantiate these interpretations.

Together, these data and the data on the phylogenetic distribution and molecular phylogeny of MACITs in extant metazoans, lead us to propose to the following model for MACIT evolution (Fig. 9). It is inferred that the MACIT ancestral gene originated in the last

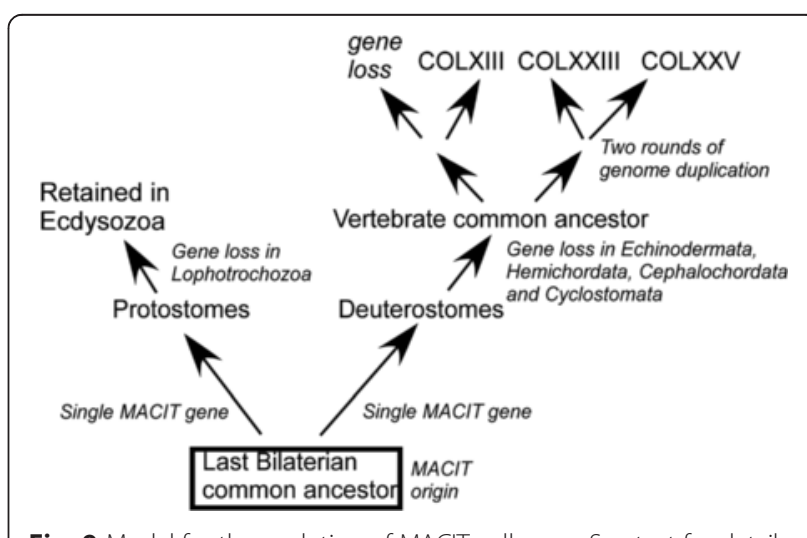

Fig. 9 Model for the evolution of MACIT collagens. See text for details 
bilaterian common ancestor, and has been conserved as a single gene in Ecdysozoa (arthropods and nematodes), Hemichordata and Urochordata, whereas the gene has been lost in the Lophotrochozoa and certain deuterostome phyla (Echinoderma, Cephalochordata and Cyclostomata). Indeed, lampreys are known to have multiple distinct proteins within their ECM, including noncollagenous cartilaginous ECM proteins such as lamprin [49]. The two rounds of en-bloc genome duplication that took place early in the vertebrate lineage then led to the origin of a family of MACIT paralogues, with loss of a putative fourth family member soon after the initial gene duplication events. The observed closer sequence relationship of collagen XXIII and XXV proteins are explained most parsimoniously by the model that these represent the extant forms arising from one pair of duplicated genes produced in the second round of genome duplication (Fig. 9). Thus, collagen XXIII and XXV genes have had a shorter time for divergence from each other than from the collagen XIII gene. The formation of a distinct clade by collagen XIII in the phylogenetic tree is taken to indicate that collagen XIII represents the single remaining member from the second pair of duplicated genes (Fig. 9). An alternative or additional possibility is that collagen XIII may be under different selection pressures and evolving at a different rate from collagens XXIII and XXV.

Through the phylogenetic studies, we identified col-99 as the sole C. elegans homologue of the mammalian MACIT collagens. To examine the possibility of functional conservation between an evolutionarily distant MACIT with the mammalian MACITs, we focused on col-99. Alternative splicing of collagen XIII with complicated exon deletions was discovered in our early gene transcription studies in human and mice. The untranscribed exons encode collagenous, or non-collagenous sequences, as well as partly collagenous and partly noncollagenous domains. All splice variants maintain the transmembrane domain, furin cleavage site and the Cterminal conserved peptide [50-52]. Due to the limited studies of collagen XXIII and XXV, alternative splicing of transcripts from these genes has not yet been adequately documented. Only two splicing variants of collagen XXV are listed in the NCBI non-redundant protein database (http://www.ncbi.nlm.nih.gov/protein/). Nevertheless, the new data on C. elegans col-99 alternative splicing suggest that complex combinations of exon deletion are a common phenomenon in MACIT collagen genes.

To characterize the C. elegans COL-99 protein, we generated the fosmid-based col-99::egfp::flag worm line, $\mathrm{CHO}$ cells expressing COL-99, and for purposes of comparison, also cells expressing human collagen XIII, as well as two C. elegans COL-99-specific antibodies. Our experiments with the transfected $\mathrm{CHO}$ cells demonstrated that col-99 encodes a protein of $85 \mathrm{kD}$, perfectly matching in size with human collagen XIII produced in the same cells. Like human collagen XIII, COL-99 has the biochemical and localization properties of a plasma membrane-associated protein. Moreover, our results identify that the predicted furin cleavage sites in the COL-99 NC1 domain are used by furin-like proteases for shedding of the ectodomain. We also identified in the worms a trimeric protein corresponding in size to that expected for the col-99::egfp::flag transgene.

The mRNA and protein levels of collagens XIII/XXIII/ XXV in human and mouse tissues and cells are generally low $[5,6,53-56]$. However, increased expression of collagens XIII and XXIII are detected during cancer development $[12,13,56]$. Data from a systematic developmental gene expression time-course study suggest that mRNA levels of col-99 in C. elegans are also low [57, 58]. The microarray data suggested slight up-regulation of the col99 mRNA in the embryonic developmental stages of ventral enclosure, embryo movement and L1 larva. This was also observed in the related species including C. remanei, C. briggsae, and C. brenneri [59].

We used the new col-99::egfp::flag C. elegans line to examine the tissue localization of COL-99 in the animals. Since the fosmid-based expression is under endogenous cis regulatory control by way of including introns and 5'and 3' UTR sequences [24], the expression patterns of COL-99-EGFP-FLAG in C. elegans should correspond well with those of the endogenous protein. In larvae and adult animals, COL-99 expression was detected in mouth, pharynx, body wall and the tail, mostly in motor neurons and muscle. Especially notable was the co-localization of COL-99::EGFP::FLAG in adult worms and embryos with the NMJ marker $\alpha$-bungarotoxin. It should be noted that in the late three-fold stage the worm can move inside the egg by rolling around its longitudinal axis, indicating advanced motor system development (http://www.wormatlas.org/).

Studies of MACIT collagens in humans and mice have suggested that these collagens have pathophysiological roles in the nervous system, in developmental innervation of muscles and at the NMJ $[9,11]$. The expression of COL-99::EGFP::FLAG at the NMJ in worm embryos together with the neuromuscular phenotypes of collagen XIII and collagen XXV knockout mice suggests that MACIT collagens have conserved roles in NMJ or neuromuscular development.

\section{Conclusions}

We identify that the MACIT transmembrane collagens are widespread in bilaterians, yet have been lost from multiple lineages. We infer that MACITs originated in the last bilaterian common ancestor, thus evolved far later than the fibrillar collagens. The collagen XIII/ 
XXIII/XXV gene family members are encoded by paralogous genes that likely originated from the two rounds of en-bloc genome duplication early in vertebrate evolution. The data on C. elegans MACIT demonstrate conserved molecular properties and tissue localisations.

The combined novel insights, tools and dataset of protein sequences reported here, set up an important basis for further work. It will be important to identify the genetic interactors and functional protein ligands of COL99, to accelerate our general understanding of MACIT collagens and especially of molecular mechanisms relevant to human diseases related to collagens XIII, XXIII and XXV.

\section{Methods}

\section{Assembly of a dataset of collagens homologous to collagens XIII, XXIII and XXV}

The C-terminal non-collagenous sequences (NC4) of human and mouse collagen XIII [4] were used initially to identify homologues in other species by BLASTP searches at NCBI. Homologous sequences were identified in C. elegans and D. melanogaster. Further homologues were identified by BLASTP and TBLASTN searches with the protein sequences of the relevant collagens from human, C. elegans and D. melanogaster (GenBank accessions: human collagen XIII, NP_001123575.1; human collagen XXIII, NP_775736.2; human collagen XXV, NP_942014.1; D. melanogaster collagen CG43342, NP_001138061 (UniProKB accession number B7Z0K8, gene ID 7354466, FlyBase ID FBgn0259244); C. elegans COL-99, NP_001122775.2) against the NCBI nonredundant protein and nucleotide databases at default parameters and, as needed, with use of Entrez terms to search individual phyla or classes of animals. Additional databases of invertebrate genomes and transcriptomes searched were Compagen (http://compagen.zoologie.unikiel.de/index.html) [60], Echinobase (http://mandolin.caltech.edu/Echinobase/) [61], and the Japanese Lamprey Genome Project (http://jlampreygenome.imcb.a-star.edu.sg/) [32]. Sequences returned with an E-value $<1 \mathrm{e}-20$ and sequence identity spanning the length of the protein were retained for further evaluation. Each identified protein sequence was validated as a MACIT by: A) confirming that the best reciprocal BLAST hits corresponded to human transmembrane collagens XIII, XXIII and XXV (E-value $<1 \mathrm{e}-10$, most E-values are $<1 \mathrm{e}-40)$. B) Domain analysis by InterProScan (http://www.ebi.ac.uk/Tools/pfa/ iprscan5/) and detailed inspection of sequence features, especially of the C-terminal region. Predicted protein orientation and transmembrane domains were identified through the resources of the Center for Biological Sequence Analysis, Technical University of Denmark (http:// www.cbs.dtu.dk/services/). Coiled-coil regions were identified by MARCOIL (http://toolkit.tuebingen.mpg.de/ marcoil). Predicted furin cleavage sites in MACITs were identified by PrOP 1.0 [37]. C) Additional TBLASTN searches against the NCBI databases of expressed sequence tags (dbest), or transcriptome shotgun assembly (TSA) were used to obtain evidence for transcription of identified open reading frames and were used in some cases to correct the GenBank predicted protein sequences. D) Construction of phylogenetic trees to validate the clade placement of newly identified MACIT sequences.

\section{Multiple sequence alignments and phylogenetic analysis}

From the above identifications, a dataset of MACIT sequences was compiled that included representative sequences from all the phyla of animals in which MACITs had been identified (Table 1). Protein sequences were aligned in MUSCLE 3.8 [46] or webPRANK [45] through the online resources of EBI (www.ebi.ac.uk). Phylogenetic analysis based on these alignments was carried out in PhyML 3.0 [62], either without or with gap removal, using the LG amino acid substitution model [63] and 200 bootstrap cycles through the resources of phylogeny.france (http://phylogeny.lirmm.fr/phylo_cgi/index.cgi/). Tree-rendering of the Newick output was conducted in iTOL (Interactive Tree Of Life, itol.embl.de) [64].

\section{Analysis of paralogy of MACIT-encoding genes within the human genome}

Paralogy between the human COL13A1, COL23A1 and COL25A1 genes was assessed initially with the database of "paralogons in the human genome" v5.28 in which searches are made based on chromosomes or chromosomal band regions (http://wolfe.ucd.ie/dup/human5.28/ ). Chromosomal locations of the three genes were then identified by TBLASTX searches of the human genome reference assembly scaffolds at NCBI (http://blast.ncbi.nlm.nih.gov/Blast.cgi, version GRCh38.p2). For each gene, local paralogous genes were identified on the NCBI human genome Map Viewer, annotation release 104, and its associated tools.

\section{Cloning and expression of human COL13-EGFP and $C$. elegans col-99 CDNA in $\mathrm{CHO}$ cells}

Cloning of human collagen XIII (COL13)-EGFP fusion cDNA into the mammalian cell expression vector pc3.1/ Hygromycin (+) (Invitrogen) was carried out in 3 steps. 1. COL13 cDNA was produced using $1 \mu \mathrm{g}$ of total RNA extracted from a mesenchymal prostate cell line EPT1 [65], and a M-MuLV reverse transcriptase kit (Thermo Scientific) followed by PCR amplification using the COL13_forward primer containing a HindIII cleavage site and the COL-13_reverse primer containing a XhoI site (Additional file 5). A $2 \mathrm{~kb}$ DNA fragment was extracted and purified from an agarose gel, and then digested with HindIII and XhoI (New England Biolabs), 
followed by insertion into the pcDNA3.1/Hygro $(+)$ vector pre-cleaved with HindIII and XhoI. The construct was verified by HindIII/XhoI digestion and DNA sequencing. 2. The COL13 cDNA was cleaved with MfeI into two DNA fragments, $1.8 \mathrm{~kb}$ from the 5 ' end and $0.2 \mathrm{~kb}$ from the 3' end. The 3' part together with an EGFP cDNA [66] were fused by two-step overlapping PCRs using primers as previously described for a COL13 cDNA from a human brain cDNA library fused with mCherry cDNA [67]. 3. The DNA fragments HindIIICOL13 (1.8 kb)-MfeI and MfeI-COL13 (0.2 kb)-EGFPXhoI were ligated into the vector pcDNA3.1/Hygro $(+)$ pre-cleaved by HindIII and XhoI. Due to the homologous sequences of mCherry and EGFP at both termini of the cDNA, all the primers for mCherry fusion cloning [67] also worked for EGFP.

To clone col-99 cDNA, two $\mu$ l of RT-reaction products from the worm line col-99::egfp::flag (for details of the worm line, see the following section of the Methods) RNA extract were used as a template in a PCR using a Q5 High-Fidelity DNA Polymerase kit (New England BioLabs) according to the manufacture's instruction. The primers were col-99_5' containing a HindIII cleavage site, and col-99_3' containing an XhoI cleavage site (Additional file 5). A $2.3 \mathrm{~kb}$ PCR product was purified from an agarose gel and inserted into the HindIII and XhoI sites of the mammalian expression vector pc3.1 (+)/hygromycin using T4 ligase (Thermo Scientific). The ligation product was transformed to the $E$. coli strain DH5 $\alpha$, the insert sizes were verified by HindIII and XhoI cleavage, and the whole cDNA was confirmed by sequencing using the primers pc3.1_forward, col-99_middle, and pc3.1_reverse (Additional file 5).

To characterize the proteins huCOL13-EGFP and COL-99, the plasmid pc3.1(+)/Hygromycin/COL13EGFP or pc3.1(+)/Hygromycin/col-99 was transfected into $\mathrm{CHO}$ cells $\left(\mathrm{CHO}-\mathrm{K} 1\right.$, ATCC ${ }^{\bullet} \mathrm{CCL}-61^{\mathrm{TM}}$, ATCC, Manassas, VA) using the TurboFect reagent (Thermo Scientific). The same vector with an inserted EGFP cDNA was used as a transfection efficiency control. Single cell clones with stable transfection were selected and amplified by hygromycin-resistance. To analyse COL-99 shedding, the cell culture medium was replaced with serum-free DMEM and the cell culture continued for another 2 days with daily addition of ascorbate $(80 \mu \mathrm{g} /$ $\mathrm{ml})$. Proteins in the media were enriched by precipitation in $50 \%$ methanol at $-20{ }^{\circ} \mathrm{C}$, pelleted by centrifugation and dissolved in SDS-PAGE sample buffer. The cells were treated with the same amount of SDS-PAGE sample buffer. To study the subcellular localization of COL-99 by western blotting, $5 \times 10^{6} \mathrm{CHO} / \mathrm{COL}-99$ cells were harvested in $1 \mathrm{ml}$ of PBS containing Complete Protease Inhibitor Cocktail (Roche) and treated 5 times by freeze-thawing. After centrifugation at $16000 \mathrm{~g}$ for 5 mins, the supernatants, containing PBS-soluble proteins, were removed for further analyses. The pellets were extracted with $1 \mathrm{ml}$ of $70 \mathrm{mM}$ Tris, $300 \mathrm{mM} \mathrm{NaCl}, \mathrm{pH}$ 7.4, containing $1 \%$ Triton $\mathrm{X}-100$ and the same protease inhibitors, by homogenization on ice. The Triton-soluble proteins were isolated by centrifugation under the same conditions. Twenty five $\mu \mathrm{l}$ of the sample from each fraction was applied for SDS-PAGE analysis. For western blotting, the human collagen XIII-EGFP fusion protein and the control protein EGFP were detected by GFP antibody. The COL-99 protein was detected by rabbit anti-COL-99 serum AB5625.11 (antigen peptide DQLPSSDSNTDDDD, custom made by Sigma-Genosys Ltd) and AB693 (antigen peptide LVAPNGTINEDLKK, custom made by Innovagen), each at 1:1000 dilution. To test the shedding of the COL-99 ectodomain by furin-like protease, Furin Inhibitor I (Calbiochem) in $10 \mu \mathrm{l}$ methanol at final concentrations of $0,1,2,5$, or $10 \mu \mathrm{M}$ was added daily to $\mathrm{CHO} / \mathrm{COL}-99$ cells at $\sim 80 \%$ confluency growing in a 12-well plate with $1 \mathrm{ml}$ of serum-free culture medium per well. The media and cells were harvested $48 \mathrm{~h}$ post-treatment, the proteins in the medium were enriched as above, pelleted by centrifugation, and dissolved in $100 \mu \mathrm{l}$ SDS-PAGE sample buffer. Cells were lysed directly in $100 \mu \mathrm{l}$ SDS-PAGE sample buffer. Twenty five $\mu$ of each sample was loaded onto SDSPAGE gels. $\beta$-tubulin was used as a loading control for the proteins from inhibitor-treated and non-treated cell lysates. To confirm the cell membrane localization of COL99 protein, CHO/COL-99 cells were fixed with $4 \%$ PFA for $30 \mathrm{~min}$ and, after a blocking step, stained with the antibody AB5625.11. AlexaFluor 594-conjugated donkey antirabbit IgG (Life Technologies) was used as a secondary antibody for the detection. Staining with the secondary antibody only was included as a negative control. Staining was imaged with a FluoView FV 1000 (Olympus) confocal microscope using a 100X objective.

\section{Generation of worm lines expressing EGFP- and FLAG- tagged COL-99 and PAT-3 proteins}

The fosmid clones WRM0624B_B09 expressing the MACIT collagen col-99::gfp::flag and WRM0619C_E11 expressing integrin pat-3:::gfp::flag, used as a control, were obtained from the $C$. elegans TransgeneOme project [24]. These constructs encode proteins with EGFP and FLAG tags at the C-termini. The fosmid clone selection and DNA production were performed according to the protocols provided by TransgeneOme [24], and the DNA sequences were validated using an ABI3500xL Genetic Analyzer (Life Technologies)

Ballistic transformation was prepared by microparticle bombardment into C. elegans strain HT1593 [unc119 (ed3)III, Caenorhabditis Genetics Center, University of Minnesota, Twin Cities]. The fosmids obtained from TransgeneOme contain an unc-119 marker cassette 
which is used for transgene screening by rescuing lossof-function mutations in the C. elegans strain HT1593 [unc119 (ed3)III]. The bombardment was performed according to the protocol described in [68]. Shortly, L1-L3 nematodes were picked and grown on enriched peptone plates seeded with E. coli C600 (CGSC, Coli Genetic Stock Center, Yale). The worms were bleached, and the eggs were isolated and grown at $20{ }^{\circ} \mathrm{C}$ to produce the worms suitable for bombardment. The microcarrier beads for the DNA transfer were prepared as follows: $30 \mathrm{mg}$ of golden microparticles (0.3-3 $\mu \mathrm{m}$ particles, Chempur, Karlsruhe, Germany) were washed thoroughly with $70 \%$ ethanol and sterile water sequentially and resuspended in $500 \mu \mathrm{l}$ of sterile $50 \%$ glycerol to form a gold stock solution $(60 \mathrm{mg} / \mathrm{ml})$. The golden beads were coated by mixing gently for $30 \mathrm{~min} 10 \mu \mathrm{l}$ of DNA $(\sim 5 \mu \mathrm{g})$ with $100 \mu \mathrm{l}$ of gold stock solution, $100 \mu \mathrm{l}$ of $2.5 \mathrm{M} \mathrm{CaCl}_{2}$ and $40 \mu \mathrm{l}$ of $0.1 \mathrm{M}$ Spermidine (Sigma-Aldrich), followed by washing in ethanol, and resuspension in $170 \mu \mathrm{l}$ of $100 \%$ ethanol. Gene bombardment was carried out with a PDS-1000/He (Bio-Rad) using 1350 psi rupture disks according to the manufacture's protocol. After the transformation, targeted nematodes with a phenotype rescued by the marker cassette were picked after 2 weeks based on their normal movement, and the lines were further cultured. Nematodes were maintained on NGM plates at $20^{\circ} \mathrm{C}$ with the E. coli strain OP50 as a food source [69].

\section{Verification of the transgenic worm lines col-99::egfp::flag and pat-3::egfp::flag}

To verify the worm lines col-99::egfp::flag and pat3::egfp::flag, ten adult C. elegans worms from each gene bombardment line with normal movement were transferred to $100-\mathrm{mm}$ diameter NGM/OP50 plates and cultured at $20{ }^{\circ} \mathrm{C}$ for 4 days. Animals (of mixed stages) were washed thoroughly with $\mathrm{M} 9$ buffer containing $22 \mathrm{mM} \mathrm{KH}_{2} \mathrm{PO}_{4}, 42 \mathrm{mM} \mathrm{Na}_{2} \mathrm{HPO}_{4}, 90 \mathrm{mM} \mathrm{NaCl}$, and $1 \mathrm{mM} \mathrm{MgSO}$, $\mathrm{pH} 7.0$, and then disrupted in $1 \mathrm{ml}$ of TriReagent (Sigma-Aldrich) by 7 repeated freeze-thaw treatments. RNA was separated from DNA and protein by phase separation with chloroform, and then purified by a Qiagen RNeasy Mini Kit (Qiagen). RNA quality was measured by RNA Integrity Score (RIS) using an automatic QIAxcel RNA QC kit v2.0 (Qiagen). One $\mu \mathrm{g}$ of RNA with RIS $\geq 7$ was used for cDNA synthesis in $50 \mu \mathrm{l}$ using the First Strand cDNA Synthesis kit (Thermo Scientific) according to manufacturer's protocol. One $\mu \mathrm{l}$ from the Reverse Transcriptase (RT) -reaction was used as a template for PCR using Taq DNA polymerase (Thermo Scientific) and the primers GFPinternal_forward and GFPinternal_reverse (Additional file 5) that were also used for DNA sequence validation. The PCR products were analyzed on agarose gels and visualized by Midori Green DNA Stain
(Nippon Genetics) on a Gel Doc ${ }^{\mathrm{Tm}} \mathrm{XR}^{+}$System (Bio-Rad). The primers for the reference gene $t b a-1$ are tba-1_forward and tba-1_reverse, and for col-99, col-99_forward and col-99_reverse (Additional file 5).

The expression of the recombinant fusion protein in the targeted worm lines was analyzed by western blotting. Total worm protein was prepared using the TriReagent according to the manufacture's instruction. The protein pellets were dissolved in $1 \%$ SDS and the total protein amount was measured with Direct Detect (Millipore). Seventy $\mu \mathrm{g}$ of total protein per lane was applied to SDS-PAGE. In some experiments, the primary antibody was mouse anti-FLAG (Sigma Aldrich) and the secondary antibody was HRP-conjugated goat anti-mouse IgG (Sigma Aldrich), and in other experiments the primary antibody was rabbit anti-GFP (Rockland Immunochemicals), with HRP-conjugated goat anti-rabbit as the secondary antibody (Jackson ImmunoResearch Inc., PA, USA). The total protein loading per lane was calibrated on $\beta$-tubulin, detected by a monoclonal antibody recognizing $\beta$-tubulin in all eukaryotic cells (Thermo Scientific). An ECL Prime Western Blotting Detection Reagent (GE Lifesciences) was used for signal detection and the imaging was processed with ImageQuant LAS 3000 (GE Lifesciences).

\section{Worm imaging}

Animals at mixed stages were anesthetized with $10 \mathrm{mM}$ sodium azide in M9 buffer for $1 \mathrm{~h}$, mounted onto $2 \%$ agarose pads freshly prepared on microscopy glass slides, and examined immediately using LSM 780 (Zeiss) or FluoView FV 1000 (Olympus) confocal microscopes.

For whole-mount immunofluorescence staining, the worms were transferred from NGM/OP50 culture plates and washed with M9 solution. After freezing the samples at $-80{ }^{\circ} \mathrm{C}$ overnight, the animals were thawed on ice and then fixed with $0.5 \mathrm{ml}$ of cold methanol at $4{ }^{\circ} \mathrm{C}$ for 10 mins, and partly disrupted by sonication twice with Digital Sonifier Models 450 (Branson Ultrasonics Corporation) at $65 \%$ amplitude for $5 \mathrm{~s}$. After being settled on ice for 10 mins, the pellets were spun down and treated with $0.5 \mathrm{ml}$ cold acetone on ice for $10 \mathrm{~min}$, followed by washing firstly with $0.5 \mathrm{ml}$ of PBS containing $0.5 \%$ BSA and $0.05 \%$ Tween-20, and then with the same solution containing $20 \%$ glycerol for another $30 \mathrm{~min}$. The specimens were then blocked with PBS containing $2 \%$ BSA, $0.2 \%$ gelatin, $2 \%$ fat-free milk and $0.05 \%$ Tween-20, at room temperature for $2 \mathrm{~h}$. The primary and secondary antibodies were diluted in blocking solution and incubated with the worms at room temperature for $2 \mathrm{~h}$ or at $4{ }^{\circ} \mathrm{C}$ overnight. For double staining, the primary antibodies were incubated one by one. The antibodies were used at the following dilutions: rabbit anti-GFP (Molecular Probes) 1:1000, mouse anti- 
C. elegans myosin heavy chain A (DSHB, Developmental Studies Hybridoma Bank) 1:20, AlexaFluor conjugated donkey anti-rabbit IgG $(\mathrm{H}+\mathrm{L})$, donkey anti-mouse IgG $(\mathrm{H}+\mathrm{L})$, and bungarotoxin (Molecular Probes) 1:1000. After staining, the worms were transferred to glass slides with $10 \mu \mathrm{l}$ of DuoLink In Situ Mounting Medium with DAPI (Sigma-Aldrich), covered with glass cover slips and sealed with nail polish. The staining was analyzed on a FluoView FV 1000 confocal microscope (Olympus) or LSM 780 confocal microscope (Zeiss) using a 100X objective. Image reconstruction and merges were obtained in Zen Lite (Zeiss) or Image J (NIH). Specimens were also prepared on poly-L-lysine coated glass slides using a freeze-crack protocol [70], and the samples were fixed with $4 \%$ PFA at $4{ }^{\circ} \mathrm{C}$ for $2 \mathrm{~h}$. The conversion of red fluorescence to magenta and new color merging were performed in Corel PaintShop Photo ProX3 (Corel).

\section{Ethics statement}

No vertebrate animals were used for these studies and no ethical approval was required.

\section{Availability of supporting data}

The COL-99 isoform $f$ (col-99) mRNA sequence is available in GenBank with the accession number of KM875546. Table 1 lists the protein sequences on which the phylogenetic study is based and states the GenBank accession number for each protein sequence.

\section{Additional files}

Additional file 1: Protein sequence alignment of human collagens XIII, XXIII, XXV and six alternative spliced variants of COL-99. The protein sequence of the newly identified COL-99f was compared with the other COL-99 variants and human collagens XIII, XXIII and XXV. Putative furin cleavage residues in these proteins and the peptides for producing the COL-99 antibodies AB5625.11 and AB693 are highlighted in the sequence. (PDF $22 \mathrm{~kb}$ )

Additional file 2: Exon-intron alignment of COL-99 variants. All the six COL-99 variants are subject to alternative splicing affecting different exons. The newly identified COL-99f lacks exons 4, 12, 16. (PDF $80 \mathrm{~kb}$ )

Additional file 3: Western blot analysis of COL-99::EGFP::FLAG expression in C. elegans with anti-GFP or anti-FLAG antibodies. This supplemental figure indicates that both anti-GFP and anti-FLAG are able to detect COL-99::EGFP::FLAG protein in the C. elegans worm lysates, but compared to the anti-FLAG, the anti-GFP antibody detects non-specific bands. (PDF $141 \mathrm{~kb}$ )

Additional file 4: Expression of PAT-3::EGFP::FLAG in C. elegans. This supplemental figure shows strong in vivo GFP signals in worm muscles and other tissues verifying the strategy and technique in the fosmidbased transgenic worm generation. (PDF $141 \mathrm{~kb}$ )

Additional file 5: A table listing the PCR primers used in this study. All the PCR primer sequences for col-99f CDNA and human collagen XIII CDNA with EGFP tag cloning, transgenic worm line verification, and RT-PCR are provided in the table. (PDF $39 \mathrm{~kb}$ )

\section{Abbreviations}

ECM: extracellular matrix; MACIT: membrane-associated collagens with interrupted triple-helices; NMJ: neuromuscular junction.

\section{Competing interests}

The authors declare that they have no competing interests.

\section{Authors' contributions}

HT, PH, JCA, TP designed experiments. JCA performed phylogenetic analyses. $H T$, PH carried out C. elegans and molecular biology experiments. HT, PH, H-ML, JCA, TP analysed data. HT, PH, JCA, TP wrote and edited the paper. All authors read and approved the final manuscript.

\section{Acknowledgements}

We thank Dr. Antony Page for advice for work with C. elegans, the C. elegans TransgeneOme project for providing the fosmids, the E. coli Genetic Resources at Yale CGSC for providing the bacteria strains, Dr. Karl-Henning Kalland for providing the RNA samples, Dr. Kaloian Nickolov for supervising ballistic transformation, Dr. Veli-Pekka Ronkainen, Biocenter Oulu Imaging Core facility, for supervising microscopy, and Sirkka Vilmi and Aila White for the technical assistance. The nematode strain HT1593 [unc-119 (ed3)III] was provided by the Caenorhabditis Genetics Center (CGC), which is funded by the NIH Office of Research Infrastructure Programs (P40 OD010440). ECM research in JCA's laboratory is supported by MRC K018043. This work was funded to TP by Centre of Excellence Grant 2012-2017 of the Academy of Finland (284605) and the Sigrid Jusélius Foundation.

Received: 6 July 2015 Accepted: 2 December 2015

Published online: 14 December 2015

\section{References}

1. Ozbek S, Balasubramanian PG, Chiquet-Ehrismann R, Tucker RP, Adams JC. The evolution of extracellular matrix. Mol Biol Cell. 2010;21 (24):4300-5. doi:10.1091/mbc.E10-03-0251.

2. Hynes RO. The evolution of metazoan extracellular matrix. J Cell Biol. 2012; 196(6):671-9. doi:10.1083/jcb.201109041.

3. Myllyharju J, Kivirikko Kl. Collagens, modifying enzymes and their mutations in humans, flies and worms. Trends Genet. 2004;20(1):33-43.

4. Hägg P, Rehn M, Huhtala P, Väisänen T, Tamminen M, Pihlajaniemi T. Type XIII collagen is identified as a plasma membrane protein. J Biol Chem. 1998; 273(25):15590-7.

5. Hashimoto T, Wakabayashi T, Watanabe A, Kowa H, Hosoda R, Nakamura A, et al. CLAC: a novel Alzheimer amyloid plaque component derived from a transmembrane precursor, CLAC-P/collagen type XXV. EMBO J. 2002; 21(7):1524-34

6. Banyard J, Bao L, Zetter BR. Type XXIII collagen, a new transmembrane collagen identified in metastatic tumor cells. J Biol Chem. 2003;278(23): 20989-94.

7. Snellman A, Keränen MR, Hägg PO, Lamberg A, Hiltunen JK, Kivirikko KI, et al. Type XIII collagen forms homotrimers with three triple helical collagenous domains and its association into disulfide-bonded trimers is enhanced by prolyl 4-hydroxylase. J Biol Chem. 2000;275(12):8936-44.

8. Veit G, Zimina EP, Franzke CW, Kutsch S, Siebolds U, Gordon MK, et al. Shedding of collagen XXIII is mediated by furin and depends on the plasma membrane microenvironment. J Biol Chem. 2007;282(37):27424-35.

9. Latvanlehto A, Fox MA, Sormunen R, Tu H, Oikarainen T, Koski A, et al. Muscle-derived collagen XIII regulates maturation of the skeletal neuromuscular junction. J Neurosci. 2010;30(37):12230-41. doi:10.1523/JNEUROSCI.5518-09.2010.

10. Heikkinen A, Tu H, Pihlajaniemi T. Collagen XIII: a type II transmembrane protein with relevance to musculoskeletal tissues, microvessels and inflammation. Int J Biochem Cell Biol. 2012;44(5):714-7. doi:10.1016/j.biocel.2012.01.024

11. Tanaka T, Wakabayashi T, Oizumi H, Nishio S, Sato T, Harada A, et al. CLAC-P/collagen type XXV is required for the intramuscular innervation of motoneurons during neuromuscular development. J Neurosci. 2014;34(4):1370-9. doi:10.1523/JNEUROSCI.2440-13.2014.

12. Banyard J, Bao L, Hofer MD, Zurakowski D, Spivey KA, Feldman AS, et al. Collagen XXIII expression is associated with prostate cancer recurrence and distant metastases. Clin Cancer Res. 2007;13(9):2634-42.

13. Spivey KA, Banyard J, Solis LM, Wistuba II, Barletta JA, Gandhi L, et al. Collagen XXIII: a potential biomarker for the detection of primary and recurrent non-small cell lung cancer. Cancer Epidemiol Biomarkers Prev. 2010;19(5):1362-72. doi:10.1158/1055-9965.EPI-09-1095. 
14. Spivey KA, Chung I, Banyard J, Adini I, Feldman HA, Zetter BR. A role for collagen XXIII in cancer cell adhesion, anchorage-independence and metastasis. Oncogene. 2012;31(18):2362-72. doi:10.1038/onc.2011.406.

15. Johnstone IL. Cuticle collagen genes. Expression in Caenorhabditis elegans. Trends Genet. 2000;16(1):21-7.

16. Page AP, Johnstone IL. The cuticle. In: The C. elegans Research Community, editor. WormBook. March 19, 2007. doi:10.1895/wormbook.1.7.1, http:// www.wormbook.org

17. Graham PL, Johnson JJ, Wang S, Sibley MH, Gupta MC, Kramer JM. Type IV collagen is detectable in most, but not all, basement membranes of Caenorhabditis elegans and assembles on tissues that do not express it. J Cell Biol. 1997;137(5):1171-83.

18. Gupta MC, Graham PL, Kramer JM. Characterization of alpha1(IV) collagen mutations in Caenorhabditis elegans and the effects of alpha1 and alpha2(IV) mutations on type IV collagen distribution. J Cell Biol. 1997;137(5):1185-96.

19. Ackley BD, Kang SH, Crew JR, Suh C, Jin Y, Kramer JM. The basement membrane components nidogen and type XVIII collagen regulate organization of neuromuscular junctions in Caenorhabditis elegans. J Neurosci. 2003:23(9):3577-87.

20. Kamath RS, Fraser AG, Dong Y, Poulin G, Durbin R, Gotta M, et al. Systematic functional analysis of the Caenorhabditis elegans genome using RNAi. Nature. 2003;421(6920):231-7.

21. Rual JF, Ceron J, Koreth J, Hao T, Nicot AS, Hirozane-Kishikawa T, et al. Toward improving Caenorhabditis elegans phenome mapping with an ORFeome-based RNAi library. Genome Res. 2004;14(10B):2162-8.

22. Rapti G, Richmond J, Bessereau JL. A single immunoglobulin-domain protein required for clustering acetylcholine receptors in C. elegans. EMBO J. 2011;30(4):706-18. doi:10.1038/emboj.2010.355.

23. Petersen SC, Watson JD, Richmond JE, Sarov M, Walthall WW, Miller 3rd DM. A transcriptional program promotes remodeling of GABAergic synapses in Caenorhabditis elegans. J Neurosci. 2011;31(43):15362-75. doi:10.1523/JNEUROSCI.3181-11.2011.

24. Sarov M, Murray Jl, Schanze K, Pozniakovski A, Niu W, Angermann K, et al. A genome-scale resource for in vivo tag-based protein function exploration in C. elegans. Cell. 2012;150(4):855-66. doi:10.1016/j.cell.2012.08.001.

25. Thompson O, Edgley M, Strasbourger P, Flibotte S, Ewing B, Adair R, et al. The million mutation project: a new approach to genetics in Caenorhabditis elegans. Genome Res. 2013:23(10):1749-62. doi:10.1101/gr.157651.113.

26. Janke DL, Schein JE, Ha T, Franz NW, O'Neil NJ, Vatcher GP, et al. Interpreting a sequenced genome: toward a cosmid transgenic library of Caenorhabditis elegans. Genome Res. 1997;7(10):974-85.

27. Latvanlehto A, Snellman A, Tu H, Pihlajaniemi T. Type XIII collagen and some other transmembrane collagens contain two separate coiled-coi motifs, which may function as independent oligomerization domains. J Biol Chem. 2003:278(39):37590-9.

28. Snellman A, Tuomisto A, Koski A, Latvanlehto A, Pihlajaniemi T. The role of disulfide bonds and alpha-helical coiled-coils in the biosynthesis of type XIII collagen and other collagenous transmembrane proteins. J Biol Chem. 2007; 282(20):14898-905.

29. Gerstein MB, Lu Z, Van Nostrand EL, Cheng C, Arshinoff BI, Liu T, et al. Integrative analysis of the Caenorhabditis elegans genome by the modENCODE project. Science. 2010;330(6012):1775-87. doi:10.1126/science.1196914.

30. Adams MD, Celniker SE, Holt RA, Evans CA, Gocayne JD, Amanatides PG, et al. The genome sequence of Drosophila melanogaster. Science. 2000;287(5461):2185-95.

31. Smith JJ, Kuraku S, Holt C, Sauka-Spengler T, Jiang N, Campbell MS, et al. Sequencing of the sea lamprey (Petromyzon marinus) genome provides insights into vertebrate evolution. Nat Genet. 2013:45(4):415-21. doi:10.1038/ng.2568. 421e1-2

32. Mehta TK, Ravi V, Yamasaki S, Lee AP, Lian MM, Tay BH, et al. Evidence for at least six Hox clusters in the Japanese lamprey (Lethenteron japonicum). Proc Natl Acad Sci U S A. 2013:110(40):16044-9. doi:10.1073/pnas.1315760110

33. Venkatesh B, Lee AP, Ravi V, Maurya AK, Lian MM, Swann JB, et al. Elephant shark genome provides unique insights into gnathostome evolution. Nature. 2014:505(7482):174-9. doi:10.1038/nature12826.

34. Amemiya CT, Alfoldi J, Lee AP, Fan S, Philippe H, Maccallum I, et al. The African coelacanth genome provides insights into tetrapod evolution. Nature. 2013;496(7445):311-6. doi:10.1038/nature12027.

35. Salzberg Y, Ramirez-Suarez NJ, Bulow HE. The Proprotein Convertase KPC-1/ Furin Controls Branching and Self-avoidance of Sensory Dendrites in
Caenorhabditis elegans. PLoS Genet. 2014;10, e1004657. doi:10.1371/journal.pgen.1004657.

36. Thacker C, Rose AM. A look at the Caenorhabditis elegans Kex2/Subtilisinlike proprotein convertase family. Bioessays. 2000:22:545-53.

37. Duckert P, Brunak S, Blom N. Prediction of proprotein convertase cleavage sites. Protein Eng Des Sel. 2004;17(1):107-12.

38. Iwanaga T, Tsutsumi R, Noritake J, Fukata Y, Fukata M. Dynamic protein palmitoylation in cellular signaling. Prog Lipid Res. 2009;48(3-4):117-27. doi:10.1016/j.plipres.2009.02.001

39. Robinson-Rechavi M, Boussau B, Laudet V. Phylogenetic dating and characterization of gene duplications in vertebrates: the cartilaginous fish reference. Mol Biol Evol. 2004;21(3):580-6.

40. Kuraku S, Meyer A, Kuratani S. Timing of genome duplications relative to the origin of the vertebrates: did cyclostomes diverge before or after? Mo Biol Evol. 2009;26(1):47-59. doi:10.1093/molbev/msn222

41. Dehal $P$, Boore JL. Two rounds of whole genome duplication in the ancestral vertebrate. PLoS Biol. 2005;3(10), e314.

42. Bourque G, Zdobnov EM, Bork P, Pevzner PA, Tesler G. Comparative architectures of mammalian and chicken genomes reveal highly varible rates of genomic rearrangements across different lineages. Genome Res. 2005:15(1):98-110.

43. McLysaght A, Hokamp K, Wolfe KH. Extensive genomic duplication during early chordate evolution. Nat Genet. 2002;31(2):200-4

44. Nicholson AC, Malik SB, Logsdon Jr JM, Van Meir EG. Functional evolution of ADAMTS genes: evidence from analyses of phylogeny and gene organization. BMC Evol Biol. 2005;5:11

45. Löytynoja A, Goldman N. webPRANK: a phylogeny-aware multiple sequence aligner with interactive alignment browser. BMC Bioinformatics. 2010;11:579. doi:10.1186/1471-2105-11-579.

46. Edgar RC. MUSCLE: multiple sequence alignment with high accuracy and high throughput. Nucleic Acids Res. 2004;32(5):1792-7.

47. Lee M, Cram EJ, Shen B, Schwarzbauer JE. Roles for beta(pat-3) integrins in development and function of Caenorhabditis elegans muscles and gonads. J Biol Chem. 2001:276(39):36404-10.

48. Exposito JY, Valcourt U, Cluzel C, Lethias C. The fibrillar collagen family. Int J Mol Sci. 2010;11(2):407-26. doi:10.3390/ijms11020407.

49. Robson P, Wright GM, Youson JH, Keeley FW. The structure and organization of lamprin genes: multiple-copy genes with alternative splicing and convergent evolution with insect structural proteins. Mol Biol Evol. 2000;17(11):1739-52.

50. Juvonen M, Pihlajaniemi T. Characterization of the spectrum of alternative splicing of alpha 1 (XIII) collagen transcripts in HT-1080 cells and calvarial tissue resulted in identification of two previously unidentified alternatively spliced sequences, one previously unidentified exon, and nine new mRNA variants. J Biol Chem. 1992;267(34):24693-9.

51. Juvonen M, Pihlajaniemi T, Autio-Härmäinen H. Location and alternative splicing of type XIII collagen RNA in the early human placenta. Lab Invest. 1993;69(5):541-51.

52. Juvonen M, Sandberg M, Pihlajaniemi T. Patterns of expression of the six alternatively spliced exons affecting the structures of the COL1 and NC2 domains of the alpha 1(XIII) collagen chain in human tissues and cell lines. J Biol Chem. 1992;267(34):24700-7.

53. Sandberg-Lall M, Hägg PO, Wahlstrom I, Pihlajaniemi T. Type XIII collagen is widely expressed in the adult and developing human eye and accentuated in the ciliary muscle, the optic nerve and the neural retina. Exp Eye Res. 2000;70(4):401-10.

54. Sund M, Väisänen $T$, Kaukinen $S$, Ilves $M, T u ~ H$, Autio-Härmäinen $H$, et al. Distinct expression of type XIII collagen in neuronal structures and other tissues during mouse development. Matrix Biol. 2001;20(4):215-31.

55. Sund M, Ylonen $\mathrm{R}$, Tuomisto A, Sormunen $\mathrm{R}$, Tahkola J, Kvist AP, et al. Abnormal adherence junctions in the heart and reduced angiogenesis in transgenic mice overexpressing mutant type XIII collagen. EMBO J. 2001; 20(18):5153-64.

56. Väisänen T, Väisänen MR, Autio-Härmäinen H, Pihlajaniemi T. Type XIII collagen expression is induced during malignant transformation in various epithelial and mesenchymal tumours. J Pathol. 2005;207(3):324-35.

57. Sonnichsen B, Koski LB, Walsh A, Marschall P, Neumann B, Brehm M, et al. Full-genome RNAi profiling of early embryogenesis in Caenorhabditis elegans. Nature. 2005:434(7032):462-9.

58. Yanai I, Hunter CP. Comparison of diverse developmental transcriptomes reveals that coexpression of gene neighbors is not evolutionarily conserved. Genome Res. 2009;19(12):2214-20. doi:10.1101/gr.093815.109. 
59. Levin M, Hashimshony $T$, Wagner F, Yanai I. Developmental milestones punctuate gene expression in the Caenorhabditis embryo. Dev Cell. 2012; 22(5):1101-8. doi:10.1016/j.devcel.2012.04.004.

60. Hemmrich G, Bosch TC. Compagen, a comparative genomics platform for early branching metazoan animals, reveals early origins of genes regulating stem-cell differentiation. Bioessays. 2008;30(10):1010-8. doi:10.1002/bies.20813.

61. Cameron RA, Samanta M, Yuan A, He D, Davidson E. SpBase: the sea urchin genome database and web site. Nucleic Acids Res. 2009;37(Database issue): D750-4. doi:10.1093/nar/gkn887.

62. Guindon S, Dufayard JF, Lefort V, Anisimova M, Hordijk W, Gascuel O. New algorithms and methods to estimate maximum-likelihood phylogenies: assessing the performance of PhyML 3.0. Syst Biol. 2010;59(3):307-21. doi:10.1093/sysbio/syq010.

63. Le SQ, Gascuel O. An Improved General Amino Acid Replacement Matrix. Mol Biol Evol. 2008;25(7):1307-20. doi:10.1093/molbev/msn067.

64. Letunic I, Bork P. Interactive Tree Of Life v2: online annotation and display of phylogenetic trees made easy. Nucleic Acids Res. 2011;39(Web Server issue):W475-8. doi:10.1093/nar/gkr201.

65. Ke XS, Qu Y, Goldfinger N, Rostad K, Hovland R, Akslen LA, et al. Epithelial to mesenchymal transition of a primary prostate cell line with switches of cell adhesion modules but without malignant transformation. PLoS One. 2008; 3(10), e3368. doi:10.1371/journal.pone.0003368.

66. Inouye S, Tsuji Fl. Aequorea green fluorescent protein. Expression of the gene and fluorescence characteristics of the recombinant protein. FEBS Lett. 1994;341(2-3):277-80

67. Dennis J, Meehan DT, Delimont D, Zallocchi M, Perry GA, O'Brien S, et al. Collagen XIII induced in vascular endothelium mediates alpha1beta1 integrin-dependent transmigration of monocytes in renal fibrosis. Am J Pathol. 2010;177(5):2527-40. doi:10.2353/ajpath.2010.100017.

68. Praitis V, Casey E, Collar D, Austin J. Creation of low-copy integrated transgenic lines in Caenorhabditis elegans. Genetics. 2001;157(3):1217-26.

69. Brenner S. The genetics of Caenorhabditis elegans. Genetics. 1974;77(1):71-94

70. Duerr JS. Immunohistochemistry. In: WormBook. The C. elegans Research Community. 2006. doi:10.1895/wormbook.1.105.1. http://www.wormbook.org

\section{Submit your next manuscript to BioMed Central and we will help you at every step:}

- We accept pre-submission inquiries

- Our selector tool helps you to find the most relevant journal

- We provide round the clock customer support

- Convenient online submission

- Thorough peer review

- Inclusion in PubMed and all major indexing services

- Maximum visibility for your research 